\title{
Fluoxetine inhibited the activation of A1 reactive astrocyte in a mouse model of major depressive disorder through astrocytic $5-\mathrm{HT}_{2 \mathrm{~B}} \mathrm{R} /$ $\beta$-arrestin2 pathway
}

\author{
Yinquan Fang ${ }^{1 \dagger}$, Xiao Ding ${ }^{2 \dagger}$, Yihe Zhang ${ }^{1}$, Lei Cai ${ }^{2}$, Yuan $\mathrm{Ge}^{2}$, Kaiyang $\mathrm{Ma}^{2}$, Rong Xu${ }^{1}$, Shanshan $\mathrm{Li}^{2}$,
} Mengmeng Song ${ }^{2}$, Hong Zhu' ${ }^{1}$, Jiaqi Liu', Jianhua Ding ${ }^{1}$, Ming Lư ${ }^{1}$ and Gang Hu${ }^{1,2^{*}}$ (c)

\begin{abstract}
Background: Fluoxetine, a selective serotonin reuptake inhibitor, has been reported to directly bind with $5-\mathrm{HT}_{2 \mathrm{~B}}$ receptor $\left(5-\mathrm{HT}_{2 \mathrm{~B}} \mathrm{R}\right)$, but the precise mechanisms, whereby fluoxetine confers the anti-depressive actions via $5-\mathrm{HT}_{2 B} \mathrm{R}$ is not fully understood. Although neuroinflammation-induced A1 astrocytes are involved in neurodegenerative diseases, the role of $\mathrm{A} 1$ astrocyte in the pathogenesis and treatment of major depressive disorder (MDD) remains unclear.

Methods: Mice were subjected to chronic mild stress (CMS) for 6 weeks and subsequently treated with fluoxetine for 4 weeks. The depressive-like and anxiety-like behaviors and the activation of A1 reactive astrocyte in hippocampus and cortex of mice were measured. Primary astrocytes were stimulated with A1 cocktail (tumor necrosis factor (TNF)- $\mathrm{a}$, interleukin (IL)-1 a and C1 q), activated (LPS) microglia-conditioned medium (MCM) or IL-6 for $24 \mathrm{~h}$ and the expression of A1-special and A2-special markers were determined using RT-qPCR and western blot. The role of $5-H T_{2 B} R$ in the effects of fluoxetine on $A 1$ reactive astrocyte was measured using $5-\mathrm{HT}_{2 B} R$ inhibitor and siRNA in vitro and AAVs in vivo. The functions of downstream signaling Gq protein and $\beta$-arrestins in the effects of fluoxetine on the activation of A1 astrocyte were determined using pharmacological inhibitor and genetic knockout, respectively.

Results: In this study, we found that fluoxetine inhibited the activation of A1 reactive astrocyte and reduced the abnormal behaviors in CMS mice, as well as ameliorated $\mathrm{A} 1$ astrocyte reactivity under three different stimulators in primary astrocytes. We also showed that astrocytic $5-\mathrm{HT}_{2 B} \mathrm{R}$ was required in the inhibitory effects of fluoxetine on $\mathrm{A} 1$ reactive astrocyte in MDD in vivo and in vitro. We further found that the functions of fluoxetine in the activation of A1 astrocyte were independent of either $\mathrm{Gq}$ protein or $\beta$-arrestin 1 in vitro. $\beta$-arrestin 2 pathway was the downstream signaling of astrocytic $5-\mathrm{HT}_{2 \mathrm{~B}} \mathrm{R}$ mediated the inhibitory effects of fluoxetine on $\mathrm{A} 1$ astrocyte reactivity in primary astrocytes and CMS mice, as well as the improved roles of fluoxetine in behavioral impairments of CMS mice.
\end{abstract}

Conclusions: These data demonstrate that fluoxetine restricts reactive $\mathrm{A} 1$ astrocyte via astrocytic $5-\mathrm{HT}_{2 \mathrm{~B}} \mathrm{R} / \mathrm{B}$-arrestin2 pathway in a mouse model of MDD and provide a novel therapeutic avenue for MDD.

\footnotetext{
*Correspondence: ghu@njmu.edu.cn

${ }^{\dagger}$ Yinquan Fang and Xiao Ding contributed equally to this work

1 Jiangsu Key Laboratory of Neurodegeneration, Department

of Pharmacology, Nanjing Medical University, 101 Longmian Avenue,

Nanjing 211166, Jiangsu, China

Full list of author information is available at the end of the article
}

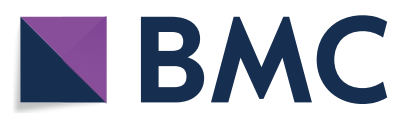

(c) The Author(s) 2022. Open Access This article is licensed under a Creative Commons Attribution 4.0 International License, which permits use, sharing, adaptation, distribution and reproduction in any medium or format, as long as you give appropriate credit to the original author(s) and the source, provide a link to the Creative Commons licence, and indicate if changes were made. The images or other third party material in this article are included in the article's Creative Commons licence, unless indicated otherwise in a credit line to the material. If material is not included in the article's Creative Commons licence and your intended use is not permitted by statutory regulation or exceeds the permitted use, you will need to obtain permission directly from the copyright holder. To view a copy of this licence, visit http://creativecommons.org/licenses/by/4.0/. The Creative Commons Public Domain Dedication waiver (http://creativeco mmons.org/publicdomain/zero/1.0/) applies to the data made available in this article, unless otherwise stated in a credit line to the data. 
Keywords: $5-\mathrm{HT}_{2 \mathrm{~B}} \mathrm{R}$, Fluoxetine, $\mathrm{A} 1$ astrocytes, Major depressive disorder, $\beta$-arrestin2

\section{Background}

Major depressive disorder (MDD) is a heterogeneous psychiatric disorder that affects more than 300 million people worldwide [1], and is one of the leading causes of disability in the world $[1,2]$. The symptoms of MDD are recurrent episodes of sadness and despondency accompanied by anhedonia, reduced concentration and energy, memory alterations and recurrent suicidal ideation, which are associated with structural and neurochemical deficits [3-5]. MDD is a multifactorial disease with various causes, including genetic susceptibility, environmental risk factors, stress and other pathological processes, such as inflammation [6-8], but the precise etiopathogenesis of MDD is not fully understood.

Current studies point to astrocyte as a potential target for novel antidepressant drugs associating with their effects on glutamatergic signaling and brain-derived neurotrophic factor levels [9]. Astrocytes are one of most abundant cell populations in the central nervous system (CNS), and play supportive roles in CNS functions, such as neurotransmitter homeostasis, blood-brain barrier integrity and synapse development and plasticity $[10,11]$. A variety of CNS diseases can be contributed to astrocyte reactivity $[12,13]$. Neuroinflammation and ischemia induced two different reactive astrocyte states, A1 and A2, respectively [14]. A1 reactive astrocytes are induced by activated microglia via secretion of specific cytokines and subsequently amplify inflammatory responses and produce neurotoxicity effects, which are involved in ageing brain and neurodegenerative diseases (NDDs) including Huntington's disease [15], amyotrophic lateral sclerosis [16] and Alzheimer's disease [14]. NLY01, a GLP1R agonist has neuroprotective effects via direct prevention of microglia mediated conversion of astrocytes to an A1 neurotoxic phenotype in models of Parkinson's disease (PD) [17], indicating that modulation of A1 astrocytes is therapeutic target of PD. Patients with MDD exhibit many features of inflammatory responses, including the increased levels of pro-inflammatory cytokines in peripheral blood, cerebrospinal fluid and brain structures as well as reactive microglia visualized by neuroimaging techniques $[18,19]$. Acute stress, such as lipopolysaccharide (LPS) and chronic social defeat stress (CSDS) stress, could induce the generation of A1 astrocytes in mice [20, 21]. Nevertheless, it remains unclear the significance of A1 astrocyte in the pathogenesis and treatment of MDD.

Fluoxetine is one of the major selective serotonin receptor inhibitors (SSRIs) and used as first-line treatment for MDD and other psychiatric disorders [22, 23].
The antidepressant action of fluoxetine is associated with increasing serotonin levels, improving neurogenesis and neuroplasticity as well as reducing inflammatory processes [23-25]. Fluoxetine also could regulate astrocytic functions, such as nutrition support, autophagy and ATP gliotransmission [25-27]. However, nothing is known about the function of fluoxetine in activation of A1 astrocyte. Several studies have found that fluoxetine is also the agonist of $5-\mathrm{HT}_{2 \mathrm{~B}}$ receptor $\left(5-\mathrm{HT}_{2 \mathrm{~B}} \mathrm{R}\right)$, a member of the $G$ protein-coupled receptor (GPCR) $[28,29]$. The therapeutic effects of fluoxetine on neurotransmission and adult neurogenesis were associated with $5-\mathrm{HT}_{2 \mathrm{~B}} \mathrm{R}[28$, 30, 31]. However, the detailed mechanisms of $5-\mathrm{HT}_{2 B} \mathrm{R}$ in the anti-depressive actions of fluoxetine remain to be elucidated.

The purposes of this study are to investigate the effects of fluoxetine on activation of A1 astrocyte in MDD, and elucidate whether its mechanism is relative to $5-\mathrm{HT}_{2 \mathrm{~B}} \mathrm{R}$. We found that fluoxetine administration relieved the depressive-like and anxiety-like behaviors in chronic mild stress (CMS) mice models. Fluoxetine also reduced A1 astrocyte reactivity in mice and primary cultured astrocytes. We also demonstrated that the function of fluoxetine in the activation of A1 astrocyte was mediated by astrocytic $5-\mathrm{HT}_{2 \mathrm{~B}} \mathrm{R}$ and dependent on the downstream $\beta$-arrestin 2 signaling pathway, while independent of either classical $G$ protein or $\beta$-arrestin1 signaling pathway. These findings illustrate that fluoxetine suppresses A1 reactive astrocyte in MDD through astrocytic $5-\mathrm{HT}_{2 \mathrm{~B}} \mathrm{R} / \mathrm{\beta}$-arrestin2 pathway, and provide a new strategy for targeting the astrocyte reactivity in the treatment of psychiatric diseases.

\section{Methods \\ Animals}

C57BL/6 J WT mice (male, 2 month old and neonatal mice) were purchased from the Animal Core Faculty of Nanjing Medical University. $\beta$-arrestin1 knockout $\left(\beta\right.$-arrestin $\left.1^{-/-}\right)$mice were purchased from the Jackson Laboratory (Las Vegas, NV, USA) and $\beta$-arrestin 2 knockout $\left(\beta\right.$-arrestin $\left.2^{-l-}\right)$ mice were obtained from Gang Pei's laboratory (Tongji University, Shanghai, China). $\beta$-arrestin $1^{-/-}$and $\beta$-arrestin $2^{-1-}$ mice were bred and maintained in the Animal Resource Centre of the Faculty of Medicine, Nanjing Medical University. If not specifically clarified, mice were allowed access to food and water ad libitum and maintained at $22-24{ }^{\circ} \mathrm{C}$. Light on/ off cycles were controlled in a 12/12 h shift. All animal experiments were carried out in compliance with the 
ethical regulations and approved by Institutional Animal Care and Use Committee of the Nanjing Medical University Experimental Animal Department.

\section{Injection of adeno-associated virus (AAV)s}

The AAV PHP.eB viruses expressing mouse $5-\mathrm{HT}_{2 \mathrm{~B}} \mathrm{R}$ small interfering RNAs (siRNA, 5- $\mathrm{HT}_{2 \mathrm{~B}} \mathrm{R}$ siRNA1/2, Additional file 1: Table S1) (AAV- $\mathrm{mHT}_{2 \mathrm{~B}} \mathrm{R}, 1.76 \mathrm{E}+13$ v.g./mL) or Control siRNA (AAV-Ctr, 1E + 13v.g./ $\mathrm{mL})$ (GeneChem Co, China) under the astrocyte-special gfaABC1D promoter were microinjected bilaterally into the hippocampal CA1 region (AP: $-2.0 \mathrm{~mm}$; ML:1.8 mm; DV:- $1.5 \mathrm{~mm}$ ) of C57BL/6 J mice (male, 2 month old) at a rate of $0.25 \mu \mathrm{L} / \mathrm{min}$ for $4 \min$ (total $1 \mu \mathrm{L}$ $\mathrm{AAVs}$ ) in a stereotaxic apparatus. After 4 weeks, the mice were subjected to CMS to develop a MDD mouse model and administrated with fluoxetine (FLX) described as followed.

\section{MDD model and drug administration}

The CMS model was developed as described previously [30, 32, 33]. Briefly, each mouse was caged singly and adapted to the environment for 3 days. Mice randomly divided into Control+saline, Control + FLX, CMS + saline, CMS + FLX groups $(n=8$ mice for each group); AAV-Ctrl + Control + saline $\quad(n=9), \quad$ AAVCtrl + Control + FLX $(n=9), \quad$ AAV-Ctrl + CMS + saline $(\mathrm{n}=11), \quad \mathrm{AAV}-\mathrm{Ctrl}+\mathrm{CMS}+\mathrm{FLX} \quad(n=12), \quad \mathrm{AAV}-$ $\mathrm{mHT}_{2 \mathrm{~B}} \mathrm{R}+$ Control + saline $(n=9), \mathrm{AAV}-\mathrm{mHT}_{2 \mathrm{~B}} \mathrm{R}+\mathrm{Con}-$ trol + FLX $\quad(n=9), \quad$ AAV- $\mathrm{mHT}_{2 \mathrm{~B}} \mathrm{R}+\mathrm{CMS}+$ saline $(n=12), \quad \mathrm{AAV}-\mathrm{mHT}_{2 \mathrm{~B}} \mathrm{R}+\mathrm{CMS}+\mathrm{FLX} \quad(n=12)$ groups; $\mathrm{WT}+$ Control + saline $\quad(n=10), \quad \mathrm{WT}+$ Control + FLX $\quad(n=10), \quad \mathrm{WT}+\mathrm{CMS}+$ saline $\quad(n=10)$, $\mathrm{WT}+\mathrm{CMS}+\mathrm{FLX} \quad(n=11), \quad \beta$-arrestin $2^{-l-}+\mathrm{Con}-$ trol + saline $\quad(\mathrm{n}=10), \quad \beta$-arrestin $2^{-l-}+$ Control + FLX $(\mathrm{n}=9), \quad \beta$-arrestin $2^{-/-}+\mathrm{CMS}+$ saline $\quad(\mathrm{n}=10)$, $\beta$-arrestin $2^{-l-}+$ CMS + FLX $(n=12)$ groups. Mice were exposed to 2-3 times randomly scheduled, mild stressors, which were not repeated for 3 consecutive days per day for 10 weeks. The mild stressors included cold water $\left(4{ }^{\circ} \mathrm{C}\right.$ for $\left.5 \mathrm{~min}\right)$, wet bedding $(12 \mathrm{~h})$, the reversal of the light-dark cycle $(24 \mathrm{~h})$, empty cage $(12 \mathrm{~h})$, restraint $(6 \mathrm{~h})$, food and water deprivation (12 h), clipping tails (3 min), strobe light $(12 \mathrm{~h})$ and cage tilting $\left(45^{\circ} \mathrm{C}, 12 \mathrm{~h}\right)$. Between 6 and 10 weeks, mice was injected with normal saline or fluoxetine $(10 \mathrm{mg} / \mathrm{kg}$, i.p., Sigma Aldrich, MO, USA) once-daily.

\section{Behavioral evaluations}

\section{Sucrose preference test (SPT)}

The SPT was performed as described previously [26]. Before test, all mice were acclimated with $1 \%$ sucrose solution for $72 \mathrm{~h}$ and then deprived of water and food for $24 \mathrm{~h}$, then, one bottle of water and one bottle of $1 \%$ sucrose solution were placed in each cage for $12 \mathrm{~h}$. After $6 \mathrm{~h}$, two bottles were exchanged to avoid location effects. The bottles were weighed before and after each test, and the sucrose preference (\%) was calculated as followed formula. Sucrose preference $(\%)=$ Consumption of sucrose solution / Consumption of sucrose solution and water $\times 100 \%$.

\section{Forced swimming test (FST)}

The FST was carried out as described by our previous studies [26, 30,34]. This test is based on the immobility time when mice are subjected to inescapable conditions [35]. Briefly, mice were individually placed in a $2 \mathrm{~L}$ glass cylinder $(13 \mathrm{~cm}$ diameter $\times 24 \mathrm{~cm}$ height $)$ filled with $14 \mathrm{~cm}$ deep water at $22{ }^{\circ} \mathrm{C}$ for $6 \mathrm{~min}$. Water was changed every trial. After adaption for $2 \mathrm{~min}$, the behaviors of mice over the next $4 \mathrm{~min}$ were recorded by a camera positioned directly in front of the cylinder and analyzed by Force Swim Scan ${ }^{\mathrm{TM}}$ software (CleverSys Inc, VA, USA).

\section{Tail suspension test (TST)}

The TST is a frequently used experiment to assess the antidepressant action [36-38]. Mice were individually suspended from the ceiling of the TST box $(50 \times 50 \times 50 \mathrm{~cm})$ by distal portion of their tails with adhesive tape at approximately $1 \mathrm{~cm}$ below the tip of the tails for 6 min. A camera was placed the front of the box and recorded the behavior of mice. The immobility time of tail-suspended mice during the last $4 \mathrm{~min}$ were analyzed by Tail suspension Scan ${ }^{\mathrm{IM}}$ software (CleverSys Inc).

\section{Open field test (OFT)}

The OFT is performed to evaluate the mental excitability of mice, which shows an exploratory behavior and a state of tension, fear, and alertness to the new environment [39]. In this test, mice were placed into the center area of each opaque box $(50 \times 50 \times 40 \mathrm{~cm})$ which is divided into a central area (side length: $35 \mathrm{~cm}$ ) and a border area. The total route of the mice within 10 min was recorded using a camera and the amount of mouse feces (a drop of urine was counted as one pellet) was counted. Before the experiment, the bottom of the box was wiped with alcohol to remove the residual odor that interferes with the behavior of mice. Bouts and duration of mice staying in the central area were analyzed by TopScan Realtime Option (CleverSys Inc).

\section{Novelty-suppressed feeding test (NSFT)}

The NSFT was performed to evaluate the anxiety of mice $[40,41]$. The experimental device and operation are similar with OFT, except that the same number of 6 peanuts with regular shapes are placed in the central area. Mice 
were put simultaneously into the corners of each box and back to peanuts after fasted for $24 \mathrm{~h}$. We then record the time of mice sniffing peanuts for more than $3 \mathrm{~s}$ or the time of chewing peanuts for the first time (The longest record does not exceed $10 \mathrm{~min}$ ).

\section{Social interaction test (SIT)}

The SIT is performed to observe the anxiety of mice through detecting the social latency [40, 41]. A perforated plastic box separates placing a social mouse randomly on one side of the opaque box and an empty plastic box on the other. The scope of the social zone is within $2 \mathrm{~cm}$ on both sides of the perforated plastic box and $2 \mathrm{~cm}$ in front of the box. The corner area is defined as a square area with a corner size of $10 \times 10 \mathrm{~cm}$ on the opposite side of the box, and the remaining area is a neutral area. Mice were placed in the center area and screened the behavior within 10 min using the camera. Recorded the timepoint when mice started to contact the social mouse for more than $3 \mathrm{~s}$.

\section{Isolation and treatment of primary cells}

Neonatal mice (within 3 days after birth) were used for the isolation of microglia as described elsewhere [42]. Briefly, after stripping the meninges and vessels, the brain tissues were treated with $0.25 \%$ trypsin/EDTA (ThermoFisher, USA) and dissociated into single cells. The cells were plated into cell adherent reagent (C1010, Applygen, Beijing, China) pre-coated T75 flasks and cultured in DMEM/F-12 (Gibco, USA), 10\% fetal bovine serum (FBS, Gibco) and 1\% streptomycin-penicillin mixture (Gibco). The mix glial cells were cultured for 10-14 $\mathrm{d}$ and the medium was changed every $3 \mathrm{~d}$. Then flasks were shaken gently at room temperature (RT) to collect the microglia. After centrifugation at $500 \mathrm{~g}$ for $10 \mathrm{~min}$, the cells were plated in 24-well plates, incubated in serum-free base medium for $1 \mathrm{~h}$, and treated with lipopolysaccharide (LPS, $100 \mathrm{ng} / \mathrm{mL}$, Sigma Aldrich) for $12 \mathrm{~h}$. The microgliaconditioned medium (MCM) were collected and centrifuged at $12,000 \mathrm{~g}$ for $10 \mathrm{~min}$ at $4{ }^{\circ} \mathrm{C}$ and the supernatant was collected to treat astrocytes. About $98 \%$ of these cells were positive for ionized calcium binding adapter molecule 1 (Iba1), a marker for microglial cell types.

Primary astrocytes were isolated from WT, $\beta$-arrestin1 $1^{-/-}$and $\beta$-arrestin $2^{-/-}$neonatal mice (within 3 days after birth) by digested with $0.25 \%$ trypsin-EDTA for $5 \mathrm{~min}$ as described [43]. The cells were cultured in DMEM (Gibco) medium containing 10\% FBS and 1\% penicillin-streptomycin mixture. The medium was changed every $3 \mathrm{~d}$. After $7 \mathrm{~d}$, the cells were split onto plates and incubated in serum-free base medium for $1 \mathrm{~h}$. About $98 \%$ of these cells were positive for glial fibrillary acidic protein (GFAP), a marker for astrocyte cell types.
Cells were pre-treated with PBS or fluoxetine $(10 \mu \mathrm{M})$ for $2 \mathrm{~h}$ as described previously [26]. Then, astrocytes were treated with following stimulators: A1 cocktail containing tumor necrosis factor (TNF)- $\alpha(30 \mathrm{ng} / \mathrm{mL}, 315-01 \mathrm{~A}$, Peprotech, USA), interleukin (IL)- $1 \alpha$ (3 ng/mL, 211-11A, Peprotech) and C1q (400 ng/mL, 204,876, Millipore, USA), MCMs as mentioned above or IL-6 $(100 \mathrm{ng} / \mathrm{ml}$, CA92590, Chemicon, USA) for 24 h. $5-\mathrm{HT}_{2 \mathrm{~B}} \mathrm{R}$ inhibitor RS-127445 (10 $\mu \mathrm{M}, \mathrm{s} 2698$, Selleck) and Gq protein inhibitor YM-254890 (100 nM, QS 3666A, AdipoGen Life Sciences, USA,) were used to pretreat astrocytes for $30 \mathrm{~min}$ before fluoxetine administration according to the manufacturer's instructions and previous report [44].

Fetuses (E15-16) from pregnant mice were used for the preparation of neurons as described previously [45]. Cortices and hippocampus were collected and dissociated with $0.125 \%$ trypsin/EDTA. Cells were plated on poly-L-lysine (PLL, $0.05 \mathrm{mg} / \mathrm{ml}$, Sigma, St Louis, MO, USA) -coated 96-well plates at a density of $5 \times 10^{5}$ cells/ $\mathrm{ml}$ in DMEM/F-12 supplemented with $10 \% \mathrm{FBS}$ and incubated at $37{ }^{\circ} \mathrm{C}$ in $5 \% \mathrm{CO} 2$ for $6 \mathrm{~h}$. Then, the media were removed and switched to neurobasal media (Gibco) with $2 \%$ B27 (Gibco) supplemented with $0.5 \mathrm{mM}$ glutamine. Culture media were changed every 3 days. After 7 days, primary neurons were lysed. About $98 \%$ of these cells were positive for microtubule-associated protein 2 (MAP2), a marker for neurons.

\section{Cell transfection}

siRNA targeting $5-\mathrm{HT}_{2 \mathrm{~B}} \mathrm{R} \quad\left(5-\mathrm{HT}_{2 \mathrm{~B}} \mathrm{R}\right.$ siRNA1) and a negative Control (NC) siRNA (GenePharma, Shanghai, China) (Additional file 1: Table S1) were transfected into astrocytes using LipofectamineTM RNAi MAX (Invitrogen, Life Technologies, CA, USA) in Opti-MEM reduced serum medium (Gibco) according to the manufacturer's instructions for $8 \mathrm{~h}$. The mixture was removed and the cells were cultured with normal medium for an additional $40 \mathrm{~h}$ (Additional file 2).

\section{Brain tissue and blood samples processing}

For immunohistochemistry (IHC) and immunofluorescence (IF), mice were anesthetized by an intraperitoneal injection of pentobarbital sodium $(60 \mathrm{mg} / \mathrm{kg}$, Sigma). After transcardial perfusion with cold PBS and 4\% paraformaldehyde (PFA), the brains were harvested, postfixed with $4 \%$ PFA overnight at $4{ }^{\circ} \mathrm{C}$ and dehydrated in 20 and $30 \%$ sucrose for 1 week. Then brain tissues were snap-frozen and cut by a Leica CM1860 cryostat (20 or $30 \mu \mathrm{m}$ thick). The brain slices were stored at $-80{ }^{\circ} \mathrm{C}$ until use. For real-time reverse transcription polymerase chain reaction (RT-qPCR), western blotting and ELISA, mice were anesthetized and perfused with cold PBS, then the brains were harvested and hippocampus and cortex 
were collected in Eppendorf tubes and stored at $-80^{\circ} \mathrm{C}$ until use. Blood samples were collected from eyeball and allowed to clot for $30 \mathrm{~min}$ at RT and overnight at $4{ }^{\circ} \mathrm{C}$. To obtain the serum the blood was centrifuged at $800 \mathrm{~g}$ for $30 \mathrm{~min}$ at $4{ }^{\circ} \mathrm{C}$ and the supernatants were centrifuged at $5000 \mathrm{~g}$ for $10 \mathrm{~min}$ at $4{ }^{\circ} \mathrm{C}$. The serum were stored at $-80{ }^{\circ} \mathrm{C}$ until use.

\section{IHC}

For immunohistochemical analysis [46], frozen $30 \mu \mathrm{m}$-thick hippocampal slices were deparaffinized with $3 \% \mathrm{H}_{2} \mathrm{O}_{2}$ for 30 min. Nonspecific antibody binding was blocked by $5 \%$ bovine serum albumin (BSA, BIOFROXX, Guangzhou, China) in PBS supplemented with $0.3 \%$ Triton X-100 for 60 min. Subsequently, the sections were incubated with GFAP (1:1000, Abcam, MA, USA, ab7260) at $4{ }^{\circ} \mathrm{C}$ overnight. After washing with PBS, the slides were incubated with goat anti-rabbit antibody (1:1000, Invitrogen) for $60 \mathrm{~min}$ at RT. The GFAP positive cells in hippocampal were detected by the DAB staining system (Boster, China), observed under a stereomicroscope (Olympus, Tokyo, Japan) for imaging, and branch number of GFAP-positive cell were calculated by Image J software (National Institutes of Health, Bethesda, Maryland, USA).

\section{IF}

IF staining was carried out as described previously [42]. Frozen $20 \mu \mathrm{m}$-thick brain sections were blocked in $5 \%$ BSA with $0.3 \%$ Triton X-100, and incubated with specific the primary antibodies, including mouse anti-GFAP (1:1000, Millipore, MAB360), rabbit anti-C3 (1:100, Abcam, ab11887), rabbit anti-Serping1 (1:500, Proteintech, IL, USA 12259-1-AP) or rabbit anti-5- $\mathrm{HT}_{2 \mathrm{~B}} \mathrm{R}$ (1:500, SAB Signalway, Nanjing, China, 32964) at $4{ }^{\circ} \mathrm{C}$ overnight. The slides were incubated with Alexa 594- or Alexa 555-conjugated secondary antibodies (1:500, Invitrogen) for $1 \mathrm{~h}$ and stained with DAPI (Invitrogen), and images were observed by confocal microscopy (Olympus) and analyzed by Image J software. The area of positive signal of GFAP, double positive signal for C3, or Serping1, and GFAP was measured using the interest grayscale threshold analysis with constant settings for minimum and maximum intensities for each staining marker [4749]. Three brain sections per mouse were used for quantification and the average of three sections was used to represent a data for each mouse.

\section{RT-qPCR}

Total RNA from mouse brain tissues or cultured astrocytes were extracted using Trizol reagent (Invitrogen), and reverse transcribed using HiScript Q RT SuperMix for qPCR Kit (Vazyme Biotech, Nanjing, China) according to the manufacturer's instructions. The cDNA obtained was mixed with AceQ qPCR SYBR Green Master Mix (High ROX Premixed) (Vazyme Biotech) and gene-specific primers (Additional file 1: Table S1) for real-time PCR in a StepOnePlus instrument (Applied Biosystems, CA, USA). The cycle time values were standardized to GAPDH of the same sample. A relative quantity was calculated using the $-\Delta \Delta C T$ (showed in heatmap) and $2^{-\Delta \Delta C T}$ (showed in bar chart) methods [17, 50].

\section{Western blotting}

Mouse tissues or primary cultured cells were lysed in RIPA buffer (50 mmol/L Tris. $\mathrm{HCl}$ (pH 7.5), $150 \mathrm{mmol} / \mathrm{L}$ $\mathrm{NaCl}, 10 \%$ Nonidet P-40 (NP-40), 0.5\% Sodium Deoxycholate, $0.1 \%$ SDS, and $1 \mathrm{mmol} / \mathrm{L}$ PMSF (add before used)) supplemented with protease inhibitor cocktail (Roche, USA). The lysates were centrifuged at $16,000 \mathrm{~g}$ for $15 \mathrm{~min}$ at $4{ }^{\circ} \mathrm{C}$, and the supernatants were used for immunoblot analysis after determining the protein concentrations by the BCA method (BCA Protein Quantitation Assay, Keygen Biotech, China). The extracts were resolved by SDS/PAGE on an $8-12 \%$ gradient separating gel and blotted on PVDF membranes (PALL Gelman, Ann Arbor, MI, USA) using Mini-PROTEAN ${ }^{\circledR}$ Tetra Handcast Systems and Mini Trans-Blot ${ }^{\circledR}$ Cell (Bio-Rad Laboratories, Hercules, CA, USA). Electrophoresis buffer (14.4 g/L Glycine, $3.0 \mathrm{~g} / \mathrm{L}$ Tris. $\mathrm{HCl}$ and $1.0 / \mathrm{L} \mathrm{SDS}$ ) and transfer buffer $(2.93 \mathrm{~g} / \mathrm{L}$ Glycine, $5.82 \mathrm{~g} / \mathrm{L}$ Tris. $\mathrm{HCl}$ and $200 \mathrm{ml} / \mathrm{L}$ Methanol) were used. The membranes were blocked for $1 \mathrm{~h}$ at room temperature with $5 \%$ fat free milk in Tris-buffered saline Tween- $20(8.0 \mathrm{~g} / \mathrm{L} \mathrm{NaCl}$, $2.4 \mathrm{~g} / \mathrm{L}$ Tris base and $1 \mathrm{~mL} / \mathrm{L}$ Tween-20) and then incubated with the following primary antibodies at $4{ }^{\circ} \mathrm{C}$ overnight: rabbit anti-C3 (1:500, ThermoFisher, PA5-21,349), rabbit anti-5- $\mathrm{HT}_{2 \mathrm{~B}} \mathrm{R}$ (1:1000, $\mathrm{SAB}$ Signalway, 32,964), rabbit anti- $\beta$-arrestin1 (1:1000, Santa Cruz, CA, USA, SC-53780), rabbit anti- $\beta$-arrestin2 (1:1000, Cell Signaling Technology, USA, 3857) and mouse anti- $\beta$-actin (1:5000, YI FEI XUE Biotechnology, China, YFPA1596). After the membranes were washed three times and incubated with the corresponding HRP-conjugated secondary antibody (1:5000, YI FEI XUE Biotechnology) for $1 \mathrm{~h}$ at RT, the bands were detected by enhanced chemiluminescence western blot detection reagents (Pierce) and analyzed with the ImageQuant ${ }^{\mathrm{TM}}$ LAS 4000 imaging system (GE Healthcare, USA). The band intensity was determined by densitometry with the aid of the Bio-Rad Gel Doc XR documentation system.

\section{ELISA}

The concentrations of IL- 6 in serum, cortex and hippocampus of mice were measured using commercially 
available ELISA kits (DY406, R\&D, USA) according to the manufacturer's instructions. Serum were diluted to 5 times using Reagent Diluent (1\% BSA in PBS, pH 7.27.4, $0.2 \mu \mathrm{m}$ filtered) and the extracts of cortex and hippocampus were diluted to $5 \mathrm{mg} / \mathrm{mL}$ using RIPA buffer. Standards were diluted using Reagent Diluent and the final concentrations are 1000, 500, 250, 125, 62.5, 31.25 and $15.625 \mathrm{pg} / \mathrm{mL}$. Coat a 96-well microplate with $100 \mu \mathrm{L}$ per well of the diluted Capture Antibody and seal the plate overnight at RT. Aspirate each well and wash with Wash Buffer $\left(0.05 \%\right.$ Tween $^{\circledR} 20$ in PBS, pH 7.2-7.4) for three times. After the last wash, remove any remaining Wash Buffer by aspirating or by inverting the plate and blotting it against clean paper towels. Block plates using Reagent Diluent and incubate for $1 \mathrm{~h}$ at RT. Repeat the aspiration/wash as above and the plates are ready for sample addition. Add sample or standards (100 $\mu \mathrm{L}$ per well), cover with an adhesive strip and incubate $2 \mathrm{~h}$ at RT. Repeat the aspiration/wash as above, and add Detection Antibody (100 $\mu \mathrm{L}$ per well), cover with an adhesive strip and incubate $2 \mathrm{~h}$ at RT. Repeat the aspiration/wash as above, and then add working dilution of Streptavidin-HRP (100 $\mu \mathrm{L}$ per well), cover the plate and incubate for $20 \mathrm{~min}$ at RT. Avoid placing the plate in direct light and repeat the aspiration/wash as above, and then add Substrate Solution $(100 \mu \mathrm{L}$ per well) and incubate for $20 \mathrm{~min}$ at RT. Add Stop Solution $\left(10 \% \mathrm{H}_{2} \mathrm{SO}_{4}\right.$, $50 \mu \mathrm{L}$ per well) and gently tap the plate to ensure thorough mixing. Determine the optical density of each well immediately, using a microplate reader (Thermo) set to $450 \mathrm{~nm}$, with background correction read at $590 \mathrm{~nm}$. A linear standard curve was created according the optical density (O.D.) values and standard concentration. The concentration of the samples was then calculated using the equation of the standard curve and taking into account the dilution of each sample.

\section{Lactate dehydrogenase (LDH)release assays}

Cell viability was determined by measuring the LDH release in the supernatants of astrocytes using a
LDH assay kit (Jiancheng Bioengineering technology, Nanjing, China) according to the manufacturer's instructions.

\section{Statistical analysis}

Statistical tests were carried out using GraphPad Prism 8.0 software. The normal distribution of data was tested using the Shapiro-Wilk test. To compare two groups, Student's $t$ test was used. To compare multiple groups, two-way repeated-measures ANOVA with Tukey's post hoc test was applied. Data are presented as the means \pm SEM from at least three independent experiments. Differences were considered significant at $P<0.05$.

\section{Results}

\section{Chronic fluoxetine administration inhibits A1 astrocyte reactivity in CMS mice models}

In this study, C57BL/6 J mice were subjected to the CMS for 6 weeks to establish a mouse model of MDD and followed by chronic fluoxetine treatment for 4 weeks (Additional file 1: Fig. S1A). After CMS stimulation for 6 weeks, the sucrose preference percentage markedly decreased (5-10 weeks: $P<0.001)$, which could be significantly improved by fluoxetine treatment for 3 and 4 weeks (Fig. 1A) $(9-10$ weeks: $P<0.001)$. Then, their behavioral changes were analyzed by TST, FST, OFT, NSFT and SIT. The immobility time of mice were significantly increased in TST and FST after CMS stimulation (Fig. 1B, C) (TST: $P<0.01$ and FST: $P<0.05)$. In OFT experiments, the bouts and duration in center were reduced in mice that were exposed to CMS (Additional file 1: Fig. S1B-D) (bouts: $P<0.01$ and duration: $P<0.05)$. Moreover, the latency time of mice to the first sniff in SIT and to the first feed $>3 \mathrm{~s}$ in NSFT were increased after CMS stimulation (Additional file 1: Fig. S1E, F) $(P<0.001)$. All these depressive-like and anxiety-like behaviors induced by CMS were clearly mitigated by chronic fluoxetine administration for 4 weeks (Fig. 1B, C, Additional file 1: Fig. S1B-F) (FST, duration and NSFT: $P<0.05$; TST and bouts: $P<0.01$; SIT: $P<0.001)$. Besides, IHC and IF results showed that fluoxetine treatment also reversed

\footnotetext{
(See figure on next page.)

Fig. 1 CMS-induced depressive-like behaviors, loss of astrocyte and A1 astrocyte reactivity are rescued by fluoxetine administration. C57BL/6 J mice were subjected to CMS for 6 weeks and then intraperitoneal injected with a vehicle (Control, $0.9 \%$ saline) or fluoxetine ( $10 \mathrm{mg} / \mathrm{kg} / \mathrm{day}$ ) for another 4 weeks. A Sucrose preference percentage during 10 weeks. B, C Immobility time of mice in TST (B) and FST (C). D, E Immunofluorescence staining (D) and area (E) of GFAP ${ }^{+}$astrocyte in the hippocampus. F, G Immunohistochemical staining (F) and total branch number $(\mathbf{G})$ of GFAP ${ }^{+}$astrocyte in the hippocampus. $\mathbf{H}$ Heatmap of A1-special and A2-special transcripts in the hippocampus as analyzed by RT-qPCR. I, $\mathbf{J}$ Protein levels of C3 in the hippocampus. K-N Proportion of C3 (K, L) and Serping1 ( $\mathbf{M}, \mathbf{N})$ in astrocyte in the hippocampus. Scar bar, $20 \mu \mathrm{m}$ in $\mathbf{D}, \mathbf{K}, \mathbf{M}$; Scar bar, $40 \mu \mathrm{m}$ in $\mathbf{F}$. Quantitative data are mean \pm s.e. Data were analyzed using two-way ANOVA, then combined with Tukey's multiple comparison to assess the differences between groups. $\mathbf{A}, \mathbf{B}: n=8$ per group; $\mathbf{C}: n=9$ CON with saline and CMS with FLX, $n=8$ CMS with saline and CON with FLX; $\mathbf{D}-\mathbf{N}$ $n=4$ per group; biologically independent animals. $\mathbf{A}, \mathbf{H}:{ }^{* *} P<0.01$, and ${ }^{* * *} P<0.001$ vs respective Control mice treated with saline; ${ }^{*} P<0.05$, and ${ }^{\# \# \# P}<0.001$ vs CMS mice treated with saline. $\mathbf{B}-\mathbf{G}, \mathbf{J}, \mathbf{L}, \mathbf{N}:{ }^{*} P<0.05,{ }^{* *} P<0.01$, and ${ }^{* *} P<0.001$
} 


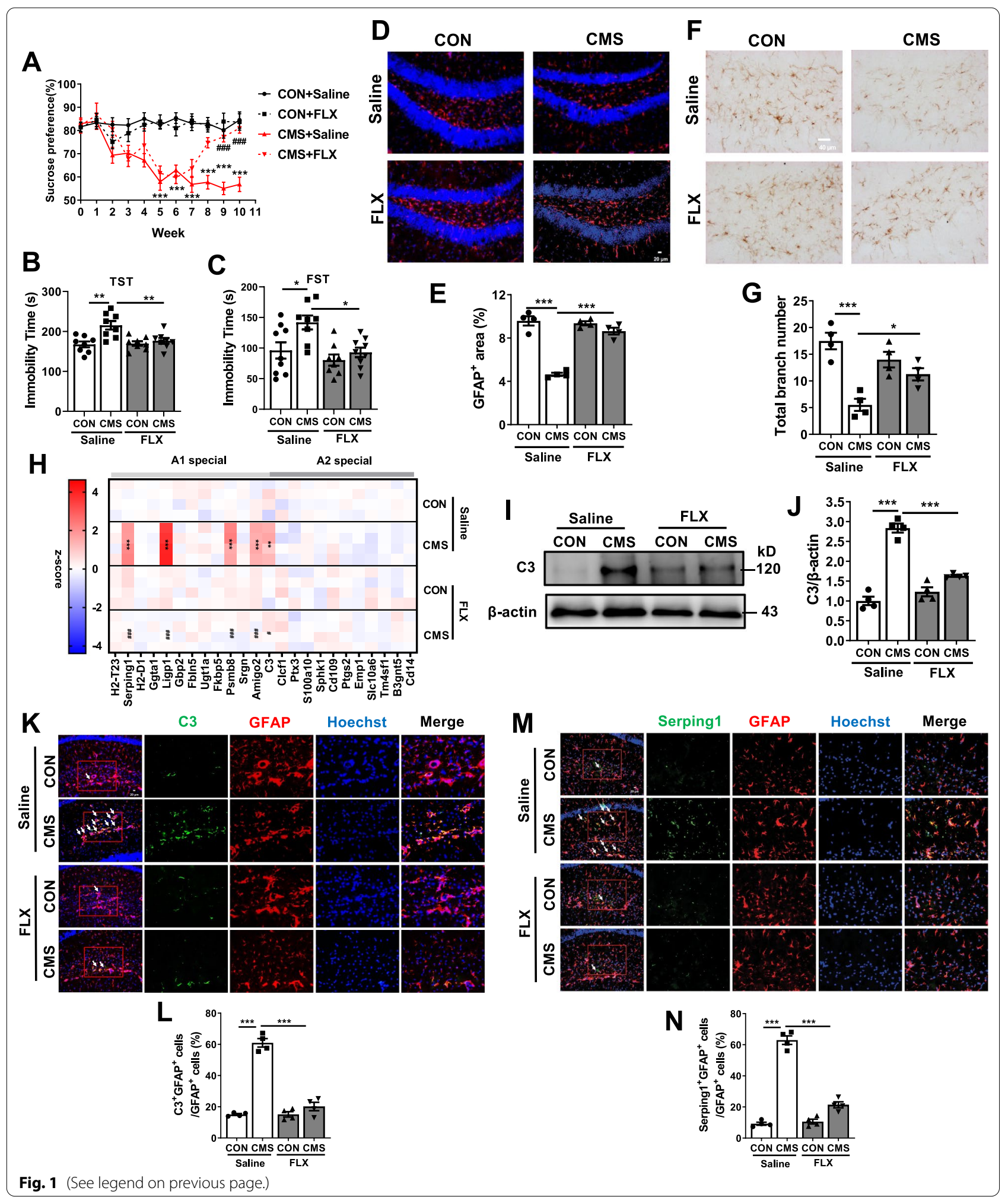

the reduction in the number and area of GFAP positive astrocytes in hippocampus of mice induced by CMS stimulation (Fig. 1D-G) (CON + saline vs CMS + saline
$P<0.001 ; \mathrm{CMS}+$ saline vs CMS + FLX $P<0.05$ in IHC; $P<0.001$ in IF). These data indicated that fluoxetine administration relieved the impairment of astrocyte in 
CMS mice. Next, we determined the effects of fluoxetine on the types of astrocyte by assessing mRNA levels of A1-specific and A2-specific markers. The transcripts of A1-specific markers (Serping1, Ligp1, Psmb8, Amigo2 and C3) were increased in hippocampus and cortex of CMS mice (hippocampus: $P<0.01$ in C3; $P<0.001$ in Serping1, Ligp1, Psmb8 and Amigo2; cortex: $P<0.001$ in Serping1, Ligp1, Psmb8, Amigo2 and C3), which was reversed by fluoxetine treatment (Fig. $1 \mathrm{H}$, Additional file 1: Fig. S2A) (hippocampus: $P<0.05$ in C3; $P<0.001$ in Serping1, Ligp1, Psmb8 and Amigo2; cortex: $P<0.001$ in Serping1, Ligp1, Psmb8, Amigo2 and C3). However, CMS stimulation and fluoxetine administration failed to affect the levels of A2-specific transcripts (Clcf1, Ptx3, S100a10, Sphk1, Cd109, Ptgs2, Emp1, Slc10a6, Tm4sf1, B3gnt5 and Cd14) in hippocampus and cortex of mice (Fig. $1 \mathrm{H}$, Additional file 1: Fig. S2A). As C3 is one of the characteristics of $\mathrm{A} 1$ astrocyte and the levels of $\mathrm{C} 3$ reflex the activation of A1 astrocyte[14], we also found that chronic fluoxetine treatment decreased the protein levels of C3 in hippocampus and cortex of CMS mice (Fig. 1I, J, Additional file 1: Fig. S2B, C) $(\mathrm{CON}+$ saline vs $\mathrm{CMS}+$ saline $P<0.01$ in cortex; $P<0.001$ in hippocampus; $C M S+$ saline vs CMS + FLX $P<0.001)$. The enhancement of the percentage of A1 astrocytes, which are C3 and GFAP double-positive $\left(\mathrm{C}^{+} \mathrm{GFAP}^{+}\right)$cells and Serping1 and GFAP double-positive (Serping $1^{+} \mathrm{GFAP}^{+}$) cells in hippocampus of CMS mice were reduced by chronic fluoxetine treatment $($ Fig. $1 \mathrm{~K}-\mathrm{N})(P<0.001)$. These findings suggest that fluoxetine decreases A1 astrocyte reactivity in the CMS mouse model, which might contribute to the antidepressant effects of this drug.

\section{Fluoxetine inhibits the activation of $\mathrm{A} 1$ astrocyte in vitro}

The production of $\mathrm{A} 1$ astrocytes were induced by three cytokines together including IL- $1 \alpha$, TNF- $\alpha$ and $\mathrm{C1q}$ which were released by activated microglia [14]. To investigate the functions of fluoxetine in the transition of A1 astrocyte in vitro, primary astrocytes (Additional file 1: Fig. S3A) were cultured and treated with A1 cocktail (TNF- $\alpha$, IL- $1 \alpha$ and C1q) or activated (LPS) microglialconditioned media (LPS-MCM) for $24 \mathrm{~h}$. Compared to control group, fluoxetine treatment reduced the enhancements in the levels of A1-specific mRNA (H2-T23, Serping1, H2-D1, Ggta1, Ligp1, Gbp2, Fbln5, Ugt1a, Fkbp5, Psmb8, Srgn, Amigo2 and C3) induced by A1 cocktail and activated MCM in astrocytes (Fig. $2 \mathrm{~A}, \mathrm{~B})(\mathrm{CON}+\mathrm{A} 1$ vs $\mathrm{CON}+\mathrm{PBS} P<0.05$ in Fkbp5, $P<0.001$ in other markers; $\mathrm{CON}+\mathrm{A} 1$ vs FLX $+\mathrm{A} 1 P<0.05$ in Fkbp5, $P<0.01$ in $\mathrm{H} 2-\mathrm{T} 23$, Amigo2 and $\mathrm{C} 3, P<0.001$ in other markers; $\mathrm{CON}+$ activated (LPS) $\mathrm{MCM}$ vs $\mathrm{CON}+$ non-activated MCM $P<0.05$ in Ugt1a, $P<0.01$ in Ggtal and Fkbp5; $P<0.001$ in other markers; CON + activated (LPS) MCM vs FLX + activated (LPS) MCM $P>0.05$ in Ugt1a, $P<0.01$ in Serping1, Ligp1, Gbp2, Fbln5, $P<0.001$ in other markers). While, A1 cocktail or LPS-MCM stimulation as well as fluoxetine administration had no effects on the expression of A2-specific transcripts in primary astrocytes (Fig. 2A, B). In addition, the protein levels of C3 were significantly enhanced in astrocytes after A1 cocktail or LPS-MCM stimulation, which were reversed by fluoxetine treatment (Fig. $2 \mathrm{C}-\mathrm{F})(\mathrm{CON}+\mathrm{A} 1$ vs $\mathrm{CON}+\mathrm{PBS}$ $P<0.01 ; \mathrm{CON}+\mathrm{A} 1$ vs $\mathrm{FLX}+\mathrm{A} 1 \quad P<0.05 ; \mathrm{CON}+$ activated (LPS) MCM vs CON+ non-activated MCM, and CON + activated (LPS) MCM vs FLX + activated (LPS) MCM $P<0.001)$. Furthermore, LDH release in supernatant was measured and the results showed that fluoxetine decreased the death of astrocyte induced by A1 cocktail and LPS-MCM stimulation (Additional file 1: Fig. S3B, C) $(\mathrm{CON}+\mathrm{A} 1$ vs $\mathrm{CON}+\mathrm{PBS}, \mathrm{CON}+\mathrm{A} 1$ vs $\mathrm{FLX}+\mathrm{A} 1$, and $\mathrm{CON}+$ activated (LPS) $\mathrm{MCM}$ vs $\mathrm{CON}+$ non-activated MCM $P<0.001 ; C O N+$ activated (LPS) MCM vs FLX + activated (LPS) MCM $P<0.05)$. Meta-analysis of adult, adolescent and children studies found a positive association between depressive symptoms and IL-6, a pleiotropic cytokine with roles in immunity [51, 52]. We showed that the levels of IL-6 were significantly increased in serum, cortex and hippocampus of mice after CMS stimulation, which were attenuated by fluoxetine treatment (Additional file 1: Fig. S2D) $(\mathrm{CON}+$ saline vs CMS + saline $P<0.05$ in hippocampus, $P<0.001$ in serum and cortex; CMS + saline vs CMS + FLX $P<0.05$ in hippocampus and cortex, $P<0.001$ in serum). We also found that although the mRNA levels of A2-special markers did not change, A1-specific markers (Serping1, Ligp1, Psmb8, Srgn, Amigo2 and C3) were increased in astrocytes after IL-6 stimulation (Fig. 2G) $(P<0.05$ in C3; $P<0.01$ in Psmb8 and Amigo2; $P<0.001$ in Serping1, Ligp1 and Srgn). Moreover, the expression of C3 protein and release of LDH were also enhanced in astrocytes after IL-6 stimulation (Fig. 2H-I, Fig. S3D) $(P<0.001)$. Fluoxetine treatment significantly blocked the activation of A1 astrocyte and release of LDH induced by IL- 6 (Fig. 2G-I, Additional file 1: Fig. S3D) $(P<0.05$ in C3, Srgn and Amigo2; $P<0.01$ in LDH; $P<0.001$ in Serping1, Ligp1 and Psmb8 and C3 protein). These data above indicate that fluoxetine inhibits the activation of A1 astrocyte under three different stimulation in vitro.

\section{The astrocytic $5-\mathrm{HT}_{2 \mathrm{~B}} \mathrm{R}$ is involved the inhibitory effects of fluoxetine on the activation of $A 1$ astrocyte in vitro and in vivo}

Previous study implied that fluoxetine has relatively high affinity with $5-\mathrm{HT}_{2 \mathrm{~B}} \mathrm{R}$ in astrocytes [28]. In this study, we found higher concentrations of $5-\mathrm{HT}_{2 \mathrm{~B}} \mathrm{R}$ proteins in primary cultured astrocytes than in primary 


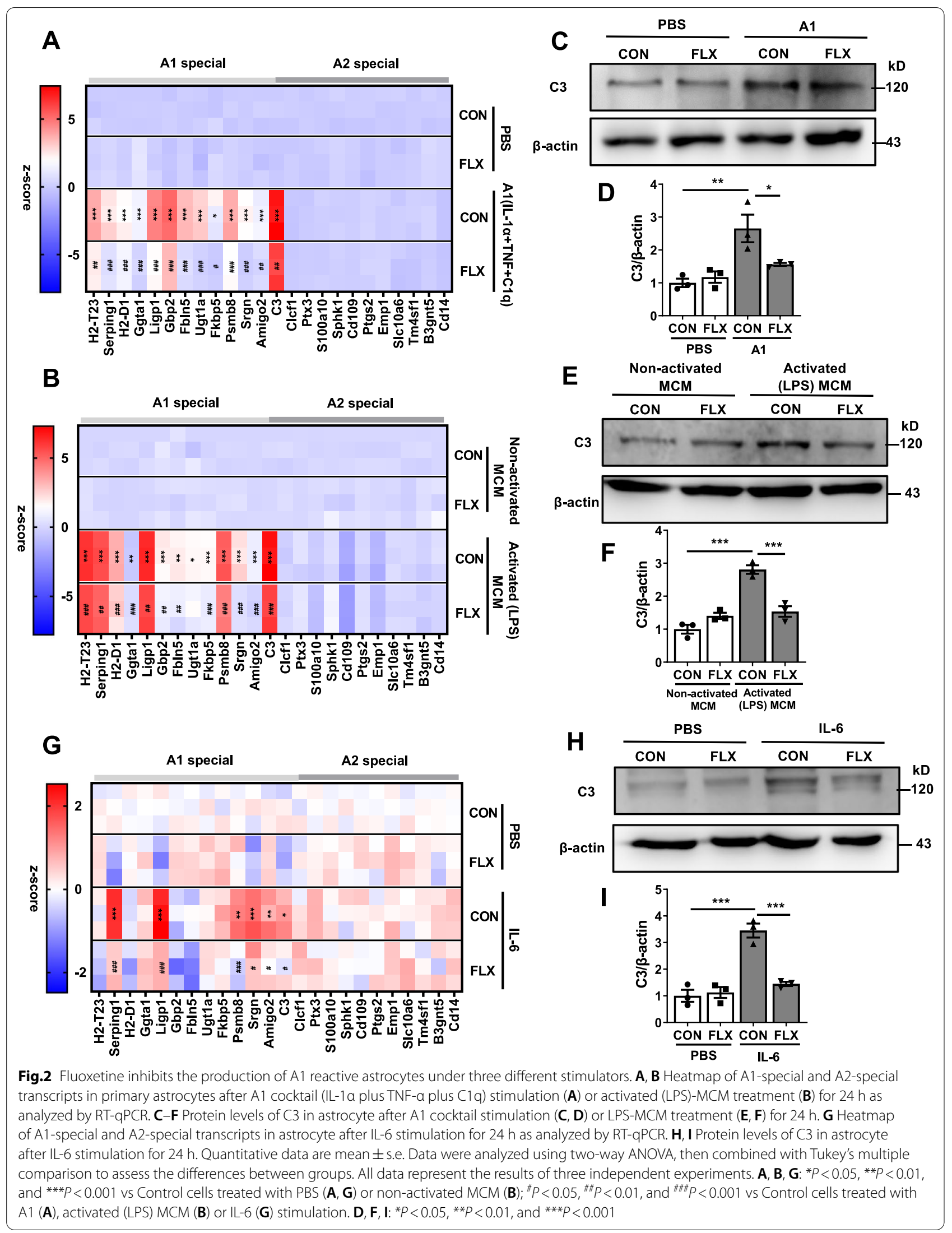




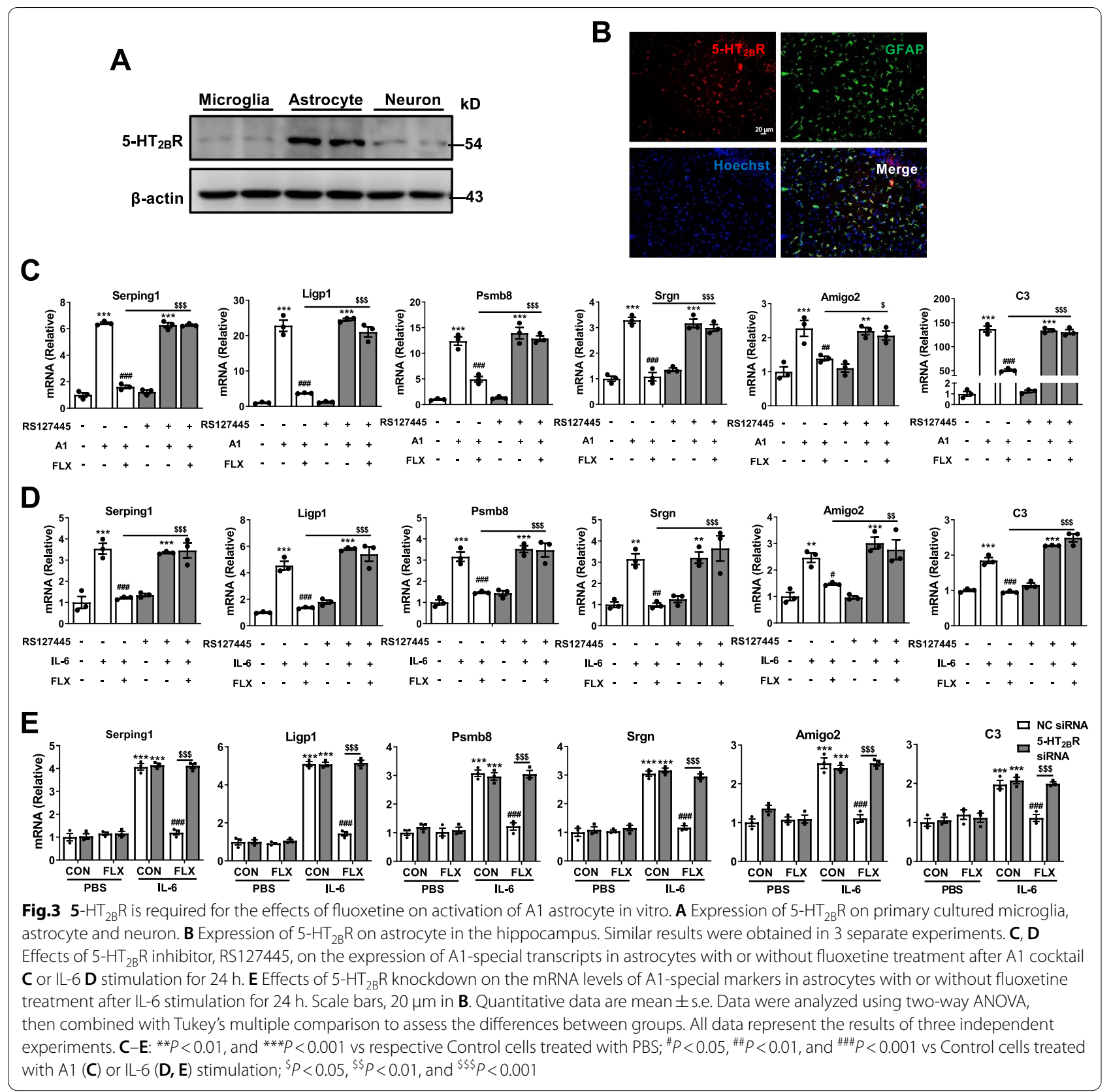

cultured microglia and neurons (Fig. 3A, Additional file 1: Fig. S3A). Immunofluorescent imaging also showed that $5-\mathrm{HT}_{2 \mathrm{~B}} \mathrm{R}$ was mainly colocalized with GFAP positive astrocytes in the hippocampus of mice (Fig. 3B). Therefore, we used $5-\mathrm{HT}_{2 \mathrm{~B}} \mathrm{R}$ inhibitor RS-127445 to investigate whether $5-\mathrm{HT}_{2 \mathrm{~B}} \mathrm{R}$ participate in the effects of fluoxetine on the $\mathrm{A} 1$ astrocyte reactivity in vitro. As shown in Fig. 3C, D, RS-127445 had no effect on the mRNA levels of A1-specific markers (Serping1, Ligp1, Psmb8, Srgn, Amigo2 and C3) in astrocytes after A1 cocktail or IL-6 stimulation, while blocked the inhibitory effects of fluoxetine on the transcripts of A1-specific markers $(\mathrm{CON}+\mathrm{A} 1$ vs $\mathrm{CON}+\mathrm{PBS} P<0.001$; $\mathrm{CON}+\mathrm{A} 1+\mathrm{RS}-127445$ vs $\mathrm{CON}+\mathrm{PBS}+\mathrm{RS}-127445$ $P<0.01$ in Amigo2; $P<0.001$ in other markers; $\mathrm{CON}+\mathrm{A} 1$ vs $\mathrm{FLX}+\mathrm{A} 1 \quad P<0.01$ in Amigo2; $P<0.001$ in other markers; FLX $+\mathrm{A} 1$ vs FLX $+\mathrm{A} 1+\mathrm{RS}-127445 P<0.05$ in Amigo2; $P<0.001$ in other markers; CON + IL-6 vs $C O N+$ PBS $P<0.01$ in Srgn and Amigo2; $P<0.001$ in other markers; CON + IL-6+RS-127445 vs $\mathrm{CON}+\mathrm{PBS}+\mathrm{RS}-127445 \quad P<0.01$ in Srgn; $P<0.001$ in other markers; CON+IL-6 vs FLX+IL-6 $P<0.05$ 
in Amigo2; $P<0.01$ in Srgn; $P<0.001$ in other markers; FLX + IL-6 vs FLX+IL-6+RS-127445 $P<0.01$ in Amigo2; $P<0.001$ in other markers). Next, the expression of $5-\mathrm{HT}_{2 \mathrm{~B}} \mathrm{R}$ was reduced by siRNA (Additional file 1 : Fig. S4) and the functions of fluoxetine in the A1 astrocyte reactivity were determined using RT-qPCR. Fluoxetine treatment decreased the activation of A1 astrocyte induced by IL-6 $(P<0.001)$, which was reversed by $5-\mathrm{HT}_{2 \mathrm{~B}} \mathrm{R}$ knockdown in astrocytes (Fig. $\left.3 \mathrm{E}\right)(P<0.001)$. These results suggest that $5-\mathrm{HT}_{2 \mathrm{~B}} \mathrm{R}$ contributes to the inhibitory roles of fluoxetine in the A1 astrocyte reactivity in vitro.

We further elucidated the function of astrocytic $5-\mathrm{HT}_{2 \mathrm{~B}} \mathrm{R}$ in the effects of fluoxetine on $\mathrm{A} 1$ astrocyte reactivity in vivo. AAVs carrying the astrocyte-specific promoter gfaABC1D (Additional file 1: Fig. S5A) were used to knock down $5-\mathrm{HT}_{2 \mathrm{~B}} \mathrm{R}$ in astrocyte of hippocampus as confirmed by western blot and immunostaining (Additional file 1: Fig. S5B, C). After AAVs injection in the hippocampus for 4 weeks, the mice were subjected to CMS for 6 weeks and subsequently administrated with fluoxetine for 4 weeks, and then behavioral tests were measured (Additional file 1: Fig. S5D). For depressive-like behaviors, the improved functions of fluoxetine in SPT,TST and FST of CMS mice were significantly reduced by $\mathrm{AAV}$-mediated knockdown of astrocytic 5- $\mathrm{HT}_{2 \mathrm{~B}} \mathrm{R}$ (Fig. 4A, B) (AAV-Ctrl + CMS + Saline vs AAV$\mathrm{Ctrl}+\mathrm{CON}+$ Saline, and AAV- $\mathrm{mHT}_{2 \mathrm{~B}} \mathrm{R}+\mathrm{CMS}+$ Saline vs $\mathrm{AAV}-\mathrm{mHT}_{2 \mathrm{~B}} \mathrm{R}+\mathrm{CON}+$ Saline $P<0.01$ in FST; $P<0.001$ in SPT and TST; AAV-Ctrl + CMS + Saline vs AAV-Ctrl + CMS + FLX $P<0.05$ in FST; $P<0.01$ in TST and $P<0.001$ in SPT; AAV-mHT ${ }_{2 B} \mathrm{R}+\mathrm{CMS}+\mathrm{FLX}$ vs $\mathrm{AAV}-\mathrm{Ctrl}+\mathrm{CMS}+\mathrm{FLX} P<0.05$ in TST and FST; $P<0.01$ in SPT). For anxiety-like behaviors (OFT, SIT and NSFT), the attenuated roles of fluoxetine in CMS mice were also blocked by $5-\mathrm{HT}_{2 \mathrm{~B}} \mathrm{R}$ knockdown in astrocytes (Additional file 1: Fig. S6A-E) (AAV-Ctrl + CMS + Saline vs $\mathrm{AAV}-\mathrm{Ctrl}+\mathrm{CON}+$ Saline, and AAV-Ctrl + CMS + Saline vs AAV-Ctrl +CMS + FLX $P<0.05$ in NSFT; $P<0.001$ in Bouts, Duration and SIT; AAV- $\mathrm{mHT}_{2 \mathrm{~B}} \mathrm{R}+\mathrm{CMS}+$ Saline vs $\quad \mathrm{AAV}-\mathrm{mHT}_{2 \mathrm{~B}} \mathrm{R}+\mathrm{CON}+$ Saline $\quad P<0.001$; AAV$\mathrm{mHT}_{2 \mathrm{~B}} \mathrm{R}+\mathrm{CMS}+\mathrm{FLX}$ vs AAV-Ctrl+CMS + FLX $P<0.05$ in Bouts; $P<0.01$ in Duration and NSFT; $P<0.001$ in SIT). Next, we determine A1 astrocyte reactivity in mice using immunostaining, western blot and RT-qPCR. As shown in Fig. 4C-F, the percentage of $\mathrm{C}^{+}{ }^{+} \mathrm{GFAP}^{+} \mathrm{A} 1$ astrocytes and the protein levels of $\mathrm{C} 3$ in hippocampus of CMS mice were markedly decreased by fluoxetine treatment (AAV-Ctrl + CMS + Saline vs $\mathrm{AAV}-\mathrm{Ctrl}+\mathrm{CON}+$ Saline $P<0.01$ in western blot; $P<0.001$ in IF; AAV- $\mathrm{mHT}_{2 \mathrm{~B}} \mathrm{R}+\mathrm{CMS}+$ Saline vs AAV$\mathrm{mHT}_{2 \mathrm{~B}} \mathrm{R}+\mathrm{CON}+$ Saline, and AAV-Ctrl $+\mathrm{CMS}+$ Saline vs AAV-Ctrl + CMS + FLX $P<0.05$ in western blot;
$P<0.001$ in IF), which were restored by astrocytic $5-\mathrm{HT}_{2 \mathrm{~B}} \mathrm{R}$ knockdown $(P<0.05$ in western blot; $P<0.001$ in IF). In addition, the inhibitory effects of fluoxetine on the levels of A1-specific transcripts (Serping1, Ligp1, Psmb8, Amigo2 and C3) in the hippocampus and cortex of CMS mice were blocked by AAV-mediated astrocytic 5- $\mathrm{HT}_{2 \mathrm{~B}} \mathrm{R}$ knockdown (Fig. 4G, Additional file 1: Fig. S6F) $(P<0.001)$. These data indicate that astrocytic $5-\mathrm{HT}_{2 \mathrm{~B}} \mathrm{R}$ is required for the effects of fluoxetine on behavioral impairments and A1 astrocyte reactivity in CMS mice.

\section{The repressed function of fluoxetine in the $\mathrm{A} 1$ astrocyte reactivity is independent of classical $G$ protein pathway} Activation of $5-\mathrm{HT}_{2 \mathrm{~B}} \mathrm{R}$ stimulates classical $\mathrm{Gq}$ protein pathways and $\beta$-arrestins-dependent signaling, leading to diverse functions $[53,54]$. We explored the possible roles of these two signaling pathways in the effects of fluoxetine on A1 astrocyte reactivity. First, to measure the role of the classical G protein pathway, YM254890, an Gq protein inhibitor was used. As shown in Fig. 5, the enhancement in the mRNA levels of A1-special markers induced by either A1 cocktail or IL- 6 stimulation were decreased by fluoxetine treatment, and YM254890 failed to affect the above effects of fluoxetine $(\mathrm{CON}+\mathrm{A} 1$ vs $\mathrm{CON}+\mathrm{PBS}$, $\mathrm{CON}+\mathrm{A} 1+\mathrm{YM} 254890$ vs $\mathrm{CON}+\mathrm{PBS}+\mathrm{YM} 254890$, $\mathrm{CON}+\mathrm{A} 1$ vs $\mathrm{FLX}+\mathrm{A} 1$, and $\mathrm{CON}+\mathrm{A} 1+\mathrm{YM} 254890$ vs $\mathrm{FLX}+\mathrm{A} 1+\mathrm{YM} 254890 P<0.001 ; \mathrm{FLX}+\mathrm{A} 1+\mathrm{YM} 254890$ vs FLX + A1: $\quad P>0.05 ; \quad \mathrm{CON}+\mathrm{IL}-6$ vs $\mathrm{CON}+\mathrm{PBS}$ $P<0.001 ; \quad$ CON + IL-6 + YM254890 vs $\mathrm{CON}+\mathrm{PBS}+\mathrm{YM} 254890 \quad P<0.05$ in Amigo2; $P<0.01$ in Psmb8; $P<0.001$ in other markers; CON+IL-6 vs FLX + IL-6, and CON+IL-6+YM254890 vs FLX + IL-6+YM254890 $P<0.01$ in Psmb8; $P<0.001$ in other markers; FLX + IL-6 + YM254890 vs FLX + IL-6: $P>0.05)$. The data indicate that the classical $G$ protein pathway isn't the downstream signaling of astrocytic $5-\mathrm{HT}_{2 \mathrm{~B}} \mathrm{R}$ regulated the inhibitory functions of fluoxetine in $\mathrm{A} 1$ astrocyte activation.

\section{Inhibitory effects of fluoxetine on the A1 astrocyte reactivity are dependent on $\beta$-arrestin2-mediated pathway} $\beta$-arrestins have two isoforms, $\beta$-arrestin1 and $\beta$-arrestin2, which regulate diverse physiological and pathophysiological processes [55]. We explored the roles of $\beta$-arrestin 1 and $\beta$-arrestin2 in the inhibitory effects of fluoxetine on the activation of A1 reactive astrocyte by knocking out them separately. There were no changes in the mRNA expressions of A1 markers between WT and $\beta$-arrestin1-deficient (Additional file 1: Fig. S7A) astrocytes after fluoxetine treatment with or without A1 cocktail and IL-6 stimulation (Fig. 6) (WT CON + A1 vs WT $\mathrm{CON}+\mathrm{PBS}, \quad \beta$-arrestin1 $1^{-/-} \mathrm{CON}+\mathrm{A} 1$ vs $\beta$-arrestin $1^{-/-} \mathrm{CON}+\mathrm{PBS}$, and $\beta$-arrestin $1^{-/-} \mathrm{FLX}+\mathrm{A} 1$ 

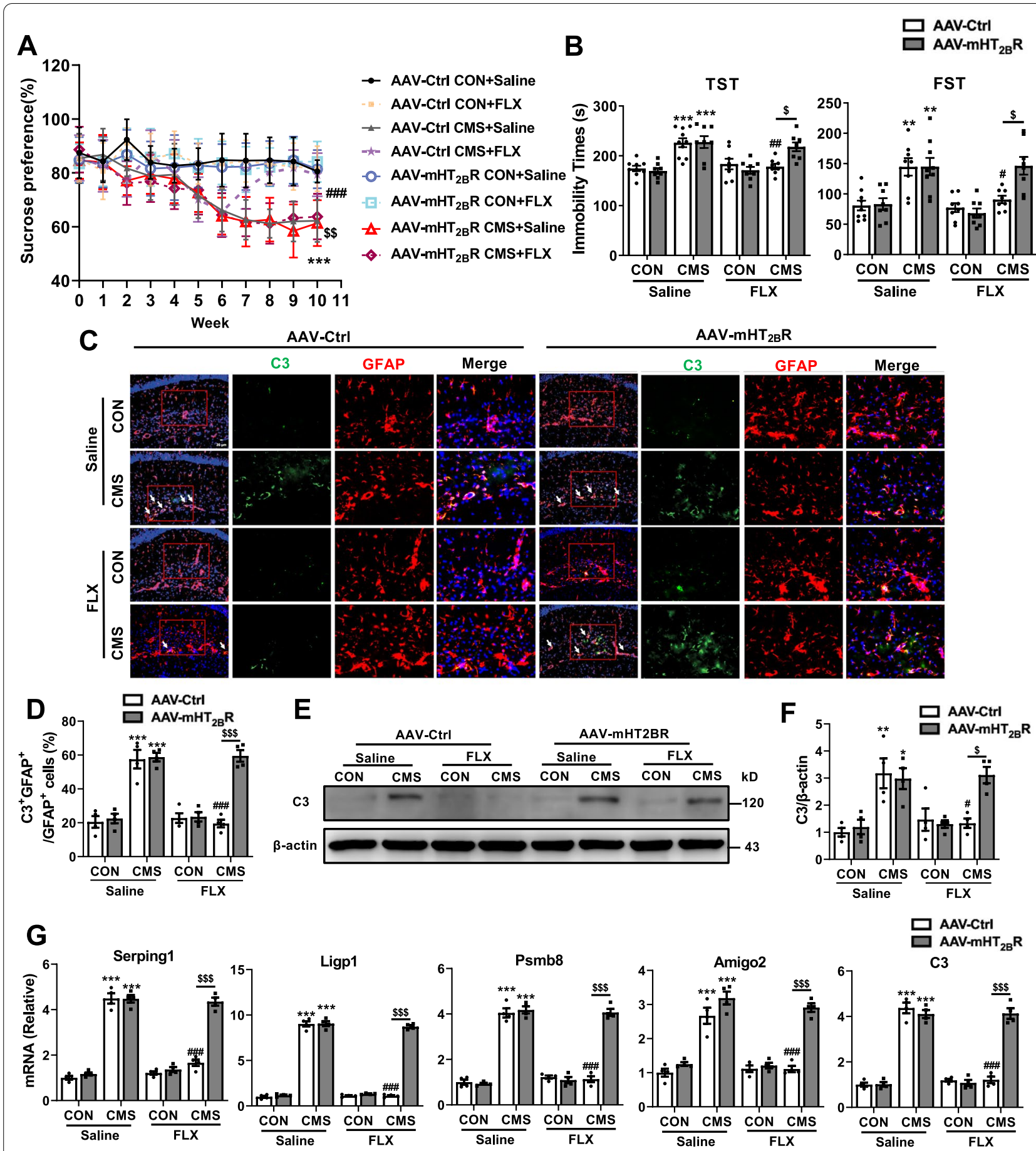

Fig. 4 Astrocytic $5-H_{2 B} R$ knockdown blocks effects of fluoxetine on CMS-induced depressive-like behaviors and A1 astrocyte reactivity. A Sucrose preference percentage of mice during 10 week treatment after AAV injection for 4 weeks. B Immobility time of mice in TST and FST. C, D Expression of C3 on astrocyte in the hippocampus DG of CON and CMS mice after AAV injection. E, F Protein levels of C3 in the hippocampus. G The levels of A1-special genes in the hippocampus. Scar bar, $20 \mu \mathrm{m}$ in C. Quantitative data are mean \pm s.e. Data were analyzed using two-way ANOVA, then combined with Tukey's multiple comparison to assess the differences between groups. $\mathbf{A}, \mathbf{B}: n=9$ CON with Control AAV and saline; $n=8$ (B), $n=9$ (A) CON with Control AAV and FLX; $n=8$ (B-FST), $n=10$ (A, B-TST) CMS with Control AAV and saline; $n=8(\mathbf{B}), n=10$ (A) CMS with Control AAV and $\mathrm{FLX} ; n=8 \mathrm{CON}$ with $\mathrm{mHT}_{2 \mathrm{~B}} \mathrm{R}$ AAV and saline; $n=8 \mathrm{CON}$ with $\mathrm{mHT}_{2 \mathrm{~B}} \mathrm{R} \mathrm{AAV}$ and $\mathrm{FLX} ; n=8$ (B-TST), $n=9(\mathbf{A}, \mathbf{B}-\mathrm{FST})$ CMS with $\mathrm{mHT} \mathrm{T}_{2 \mathrm{~B}} \mathrm{R}$ AAV and saline; $n=8 \mathrm{CMS}$ with $\mathrm{mHT}_{2 \mathrm{~B}} \mathrm{R}$ AAV and FLX; $\mathbf{C}-\mathbf{G}: n=4$ per group; biologically independent animals. $\mathbf{A}:{ }^{* *} P<0.001$ vs respective Control mice treated

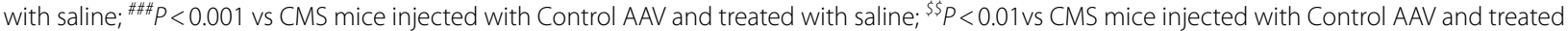
with fluoxetine; B, D, F and $\mathbf{G}:{ }^{*} P<0.05,{ }^{* *} P<0.01$, and ${ }^{* *} P<0.001$ vs respective Control mice treated with saline; ${ }^{\#} P<0.05,{ }^{\# \#} P<0.01$, and ${ }^{\# \# \#} P<0.001$ vs CMS mice injected with Control AAV and treated with saline; ${ }^{\$} P<0.05$, and ${ }^{\$ \$ \$} P<0.001$ 
A

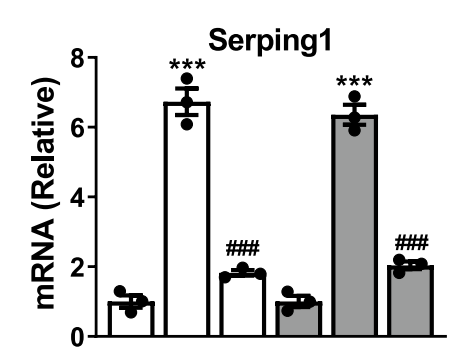

YM254890 - - - + + +
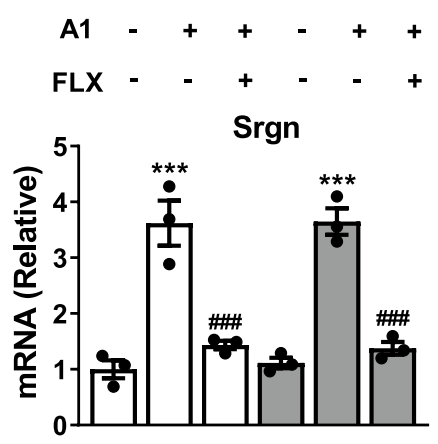

YM254890

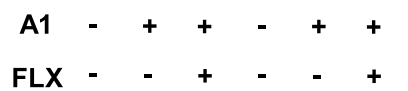

B

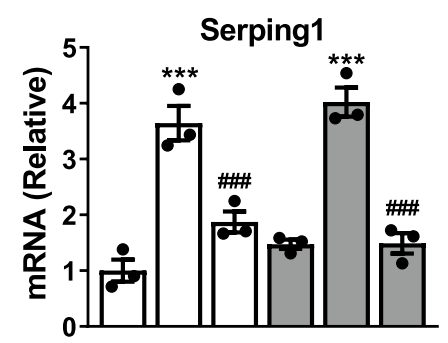

YM254890 - - - + + +

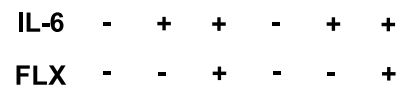

Srgn

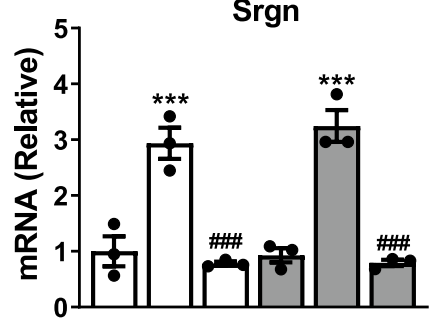

YM254890

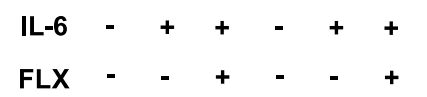

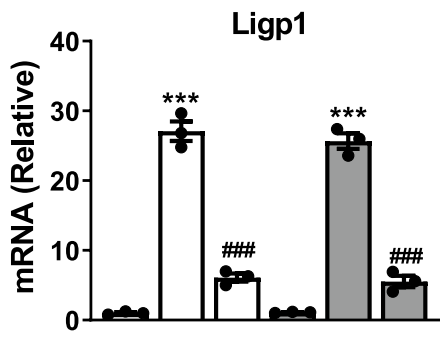

YM254890 - - - + + +

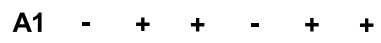

FLX - - + - - +
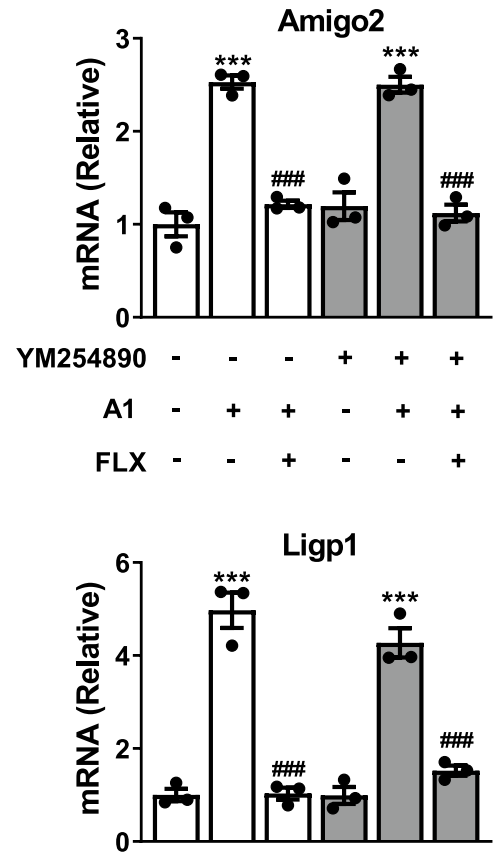

YM254890
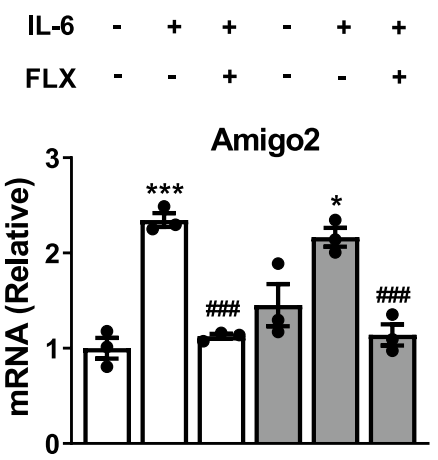

YM254890

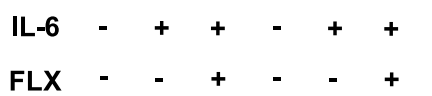

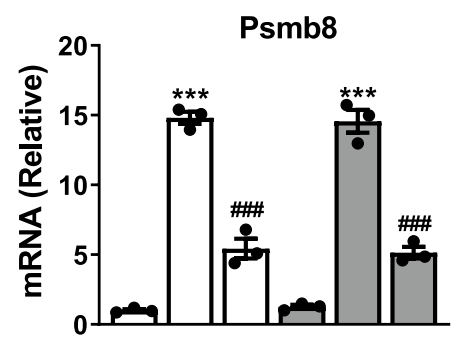

YM254890 - - - + + +
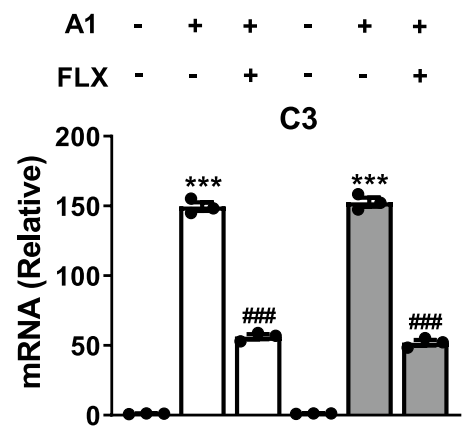

YM254890 - - - + + +

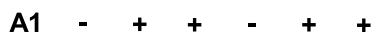

FLX - - + - - +

Psmb8

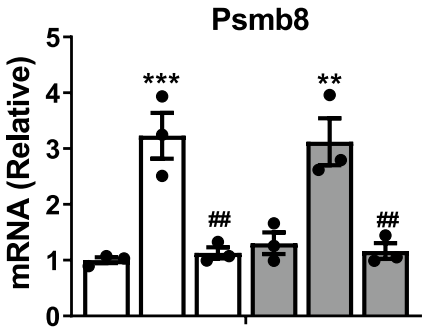

YM254890 - $\quad$ - $\quad$ - $\quad+\quad+\quad+$

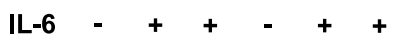

FLX - - + - - +

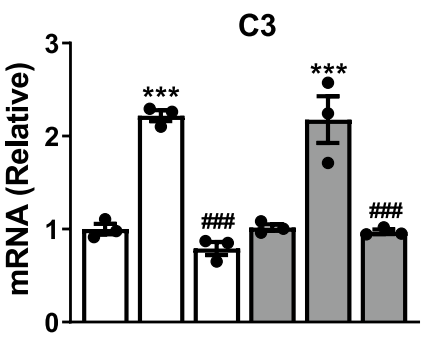

YM254890 - $\quad$ - $\quad$ - $+\quad+\quad+$

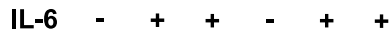

FLX - - + - - +

Fig. 5 Functions of fluoxetine in A1 astrocyte reactivity are independent of classical G protein pathways. A, B Effects of the inhibitor of Gq protein, YM-254890 on the mRNA levels of A1-special markers in astrocytes with or without fluoxetine treatment after A1 (A) or IL-6 (B) stimulation. Quantitative data are mean \pm s.e. Data were analyzed using two-way ANOVA, then combined with Tukey's multiple comparison to assess the differences between groups. All data represent the results of three independent experiments. ${ }^{*} P<0.01$, and ${ }^{* * *} P<0.001$ vs respective Control cells treated with PBS; ${ }^{\# \#} P<0.01$, and ${ }^{\# \#} P<0.001$ vs Control cells treated with A1 (A) or IL-6 (B) stimulation 


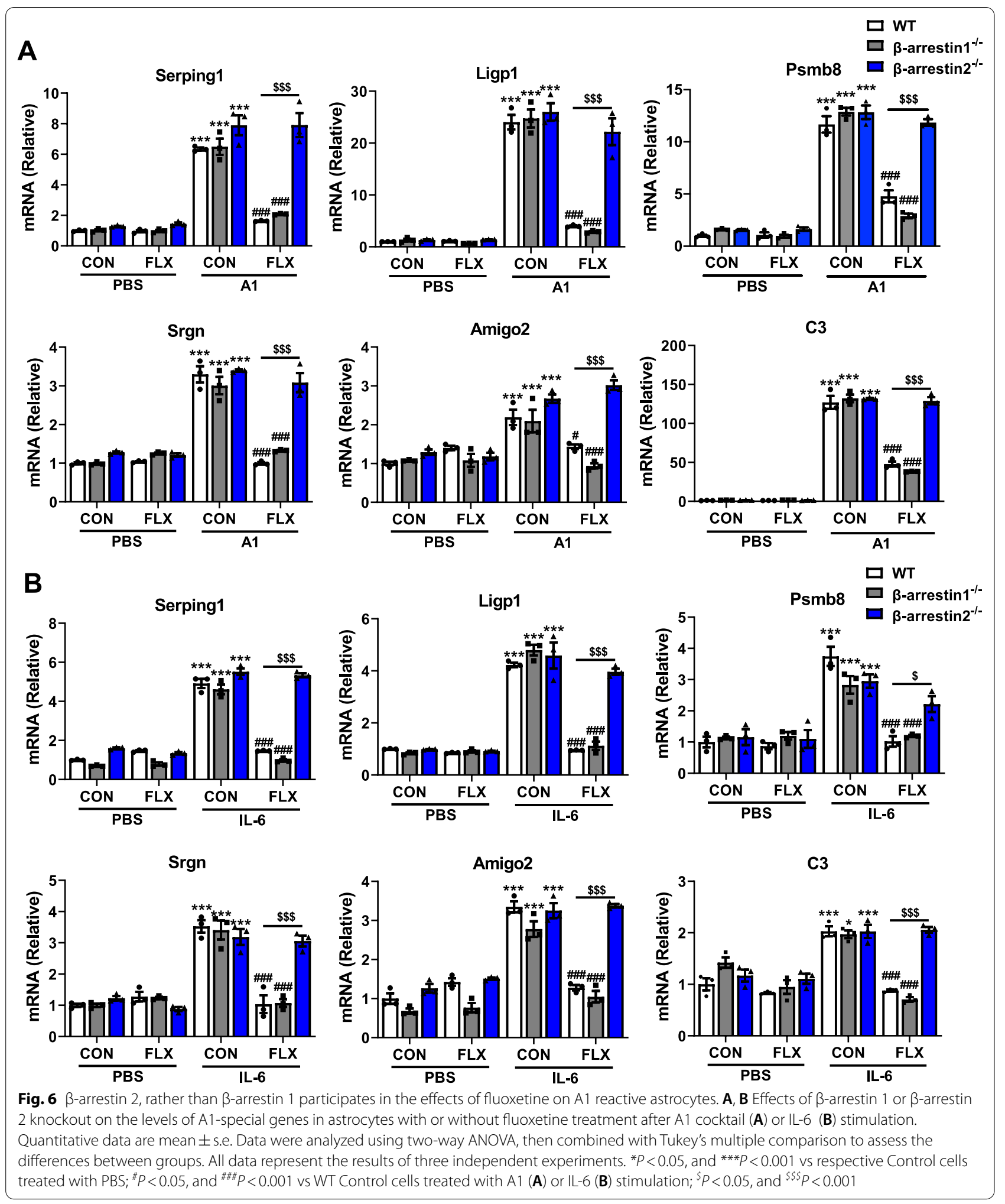


vs $\beta$-arrestin1 $1^{-l-}$ CON + A1 $P<0.001 ;$ WT FLX + A1 vs WT CON + A1 $P<0.05$ in Amigo2; $P<0.001$ in other markers; $\beta$-arrestin1 ${ }^{-/-}$FLX $+\mathrm{A} 1$ vs WT FLX $+\mathrm{A} 1$ $P>0.05$; WT $\mathrm{CON}+\mathrm{IL}-6$ vs $\mathrm{WT} \mathrm{CON}+\mathrm{PBS}$, WT FLX+IL-6 vs WT CON+IL-6, and $\beta$-arrestin $1^{-1-}$ FLX + IL-6 vs $\beta$-arrestin $1^{-1-}$ CON+IL-6 $\quad P<0.001$; $\beta$-arrestin $1^{-1-}$ CON + IL- 6 vs $\beta$-arrestin $1^{-1-}$ CON + PBS $P<0.05$ in C3; $P<0.001$ in other markers; $\beta$-arrestin1 ${ }^{-1-}$ FLX+IL-6 vs WT FLX+IL-6 $P>0.05$ ). Whereas, ablation of $\beta$-arrestin2 (Additional file 1: Fig. S7B) significantly abolished the ameliorative actions of fluoxetine on the transcript levels of A1 markers in astrocytes after A1 cocktail, IL-6 and activated MCM stimulation (Fig. 6, Additional file 1: Fig. S7C) $\left(\beta\right.$-arrestin $2^{-/-} \mathrm{CON}+\mathrm{A} 1$ vs $\beta$-arrestin2 $2^{-l-}$ CON + PBS, $\beta$-arrestin2 $2^{-l-}$ FLX $+\mathrm{A} 1$ vs WT FLX $+\mathrm{A} 1$, and $\beta$-arrestin2 ${ }^{-l-} \mathrm{CON}+\mathrm{IL}-6$ vs $\beta$-arrestin2 ${ }^{-1-} \quad$ CON + PBS $\quad P<0.001 ; \quad \beta$-arrestin2 $2^{-1-}$ FLX+IL-6 vs WT FLX+IL-6 $P<0.05$ in Psmb8; $P<0.001$ in other markers; WT $\mathrm{CON}+$ activated (LPS) MCM vs WT $\mathrm{CON}+$ non-activated MCM, and $\beta$-arrestin2 ${ }^{-/-}$CON + activated (LPS) MCM vs $\beta$-arrestin $2^{-l-}$ CON+non-activated $\mathrm{MCM} \quad P<0.001$; WT FLX + activated (LPS) MCM vs WT CON + activated (LPS) MCM $P<0.01$ in C3; $P<0.001$ in other markers; $\beta$-arrestin $2^{-/-}$FLX + activated (LPS) MCM vs WT FLX + activated (LPS) MCM $P<0.01$ in Amigo2 and C3; $P<0.001$ in other markers). These results suggest that $\beta$-arrestin2, rather than $\beta$-arrestin1 is involved in the inhibitory effects of fluoxetine on activation of A1 astrocyte in vitro.

Next, we further elucidated the role of $\beta$-arrestin 2 in the effects of fluoxetine on activation of A1 astrocyte in MDD in vivo. Chronic fluoxetine treatment improved depressive-like behaviors, including decreased sucrose preference of SPT and increased immobility time of TST and FST in CMS mice, which were reversed by $\beta$-arrestin2 knockout (Fig. 7A, B) (WT CMS + Saline vs WT $\mathrm{CON}+$ Saline, $\beta$-arrestin2 ${ }^{-l-} \mathrm{CMS}+$ saline vs $\beta$-arrestin $2^{-l-}$ CON + Saline, and WT CMS + FLX vs WT CMS + Saline $P<0.001 ; \beta$-arrestin2 ${ }^{-1-}$ CMS + FLX vs WT CMS +FLX $P<0.05$ in TST and FST; $P<0.01$ in SPT). In addition, $\beta$-arrestin2 deficient blocked the improved effects of fluoxetine on anxiety-like behaviors, including increased bouts and duration in center of OFT (Additional file 1: Fig. S8A-C) (WT CMS + Saline vs $\mathrm{WT} \mathrm{CON}+$ Saline, and $\beta$-arrestin2 ${ }^{-1-} \mathrm{CMS}+$ saline vs $\beta$-arrestin $2^{-1-}$ CON + Saline $P<0.001$; WT CMS + FLX vs WT CMS + Saline, and $\beta$-arrestin2 ${ }^{-1-}$ CMS + FLX vs WT CMS + FLX $P<0.05$ in duration; $P<0.001$ in bouts) and decreased latency time of mice to the first sniff in SIT and to the first feed $>3 \mathrm{~s}$ in NSFT after CMS stimulation (Additional file 1: Fig. S8D, E) (WT CMS + Saline vs WT $\mathrm{CON}+$ Saline, $\beta$-arrestin $2^{-l-} \mathrm{CMS}+$ saline vs $\beta$-arrestin $2^{-l-}$ CON + Saline, and WT CMS + FLX vs WT CMS + Saline $P<0.001 ; \beta$-arrestin $2^{-1-}$ CMS +FLX vs WT CMS + FLX $P<0.01$ in SIT; $P<0.001$ in NSFT). We then assessed the activation of A1 astrocyte induced by CMS stimulation in WT and $\beta$-arrestin2 knockout mice with or without fluoxetine treatment. Immunostaining results showed that the proportion of A1 astrocytes in the hippocampus of CMS mice were reduced by chronic fluoxetine administration, which were abolished by $\beta$-arrestin 2 knockout (Fig. 7C, D) $(P<0.001)$. Moreover, ablation of $\beta$-arrestin2 reversed the inhibitory roles of fluoxetine in the levels of $\mathrm{C} 3$ protein in hippocampus of mice after CMS stimulation (Fig. 7E, F) $(P<0.001)$. Furthermore, the ameliorative effects of fluoxetine on the transcript levels of A1 markers in hippocampus and cortex of CMS mice were blocked by $\beta$-arrestin2 deficient (Fig. 7G, Additional file 1: Fig. S8F) $(P<0.001)$. These data suggest that $\beta$-arrestin2 participates in the functions of fluoxetine in behavioral impairments and A1 astrocyte reactivity in CMS mouse model. Collectively, $\beta$-arrestin2 pathway is a downstream effector of $5-\mathrm{HT}_{2 \mathrm{~B}} \mathrm{R}$ mediated the inhibitory effects of fluoxetine on $\mathrm{A} 1$ astrocyte reactivity in MDD in vitro and in vivo.

\section{Discussion}

In this paper, we demonstrate that fluoxetine inhibits the activation of $\mathrm{A} 1$ astrocyte in MDD through $5-\mathrm{HT}_{2 \mathrm{~B}} \mathrm{R} / \mathrm{\beta}$ arrestin2 pathway in vivo and in vitro (Additional file 1 : Fig. S9). From the results presented above, two points are particularly noteworthy. First, our study confirmed that fluoxetine inhibits A1 astrocyte reactivity both in CMS mice and primary cultured astrocytes. In many NDDs, A1 astrocytes not only have potently neurotoxic effects, but they also amplify inflammatory microglial responses $[14,17,56]$. Several postmortem studies found that reduced astrocyte densities may be related to depressive episodes, and elevated astrocyte protein S100 beta in cerebrospinal fluid serum could be a biomarker of MDD [57]. Recently studies implied that appearance of A1 astrocytes is associated with depression-like behaviors induced by LPS and acute stress [20,58]. Our in vivo data showed that fluoxetine reduced the activation of A1 astrocyte and the loss of astrocyte as well as ameliorated depressive-like and anxiety-like behaviors in CMS mice models. Moreover, our in vitro results showed that in addition to activated MCM and A1 cocktail, IL-6, a kind of cytokine that positively associated with MDD, caused higher transcript levels of A1 markers and LDH secretion in primary astrocytes, suggesting that the development of MDD is associated with the activation of A1 astrocyte. Fluoxetine treatment blocked the activation of A1 reactive astrocyte after those three kinds of stimulator. Our study indicate that the reduction of A1 astrocyte 


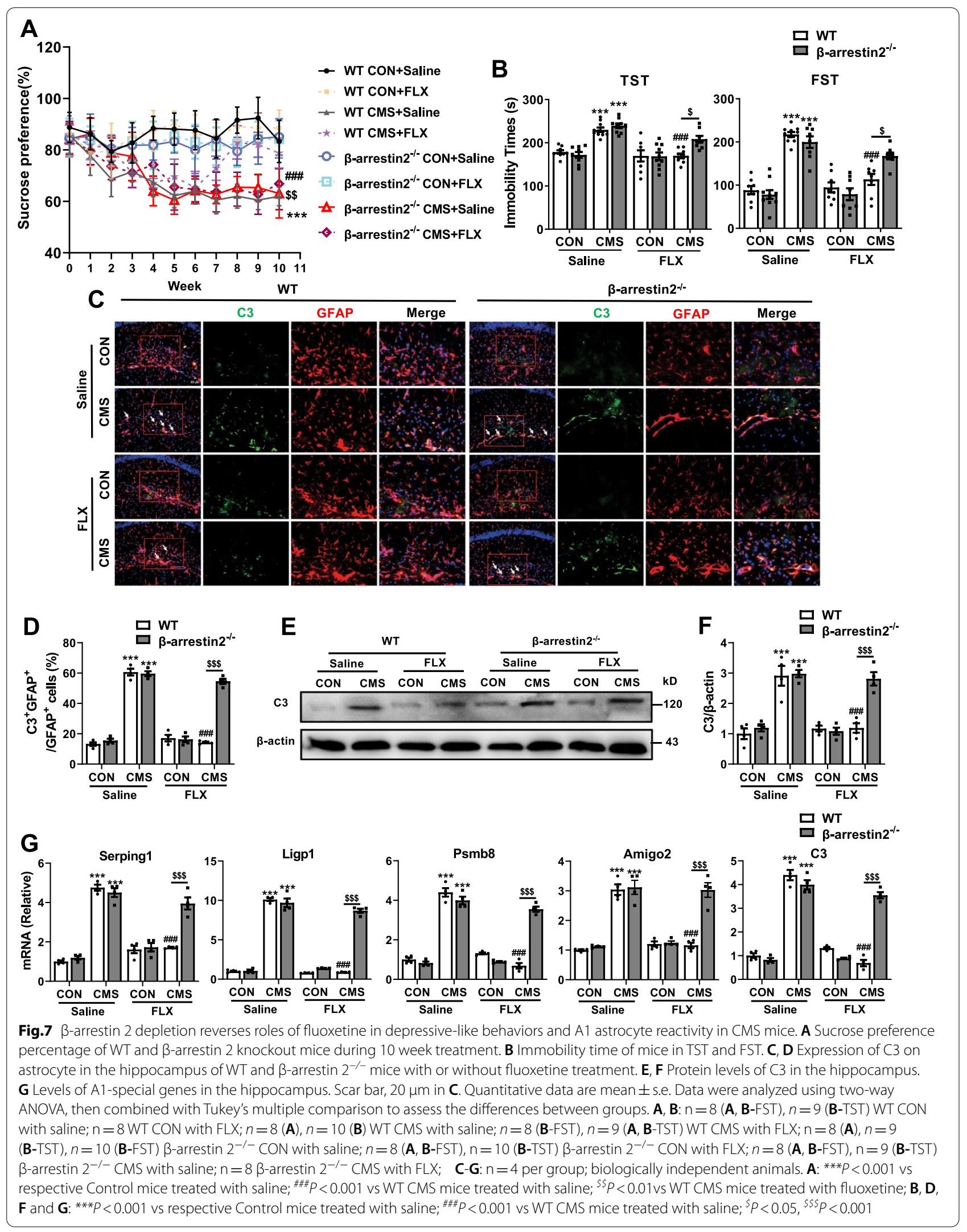




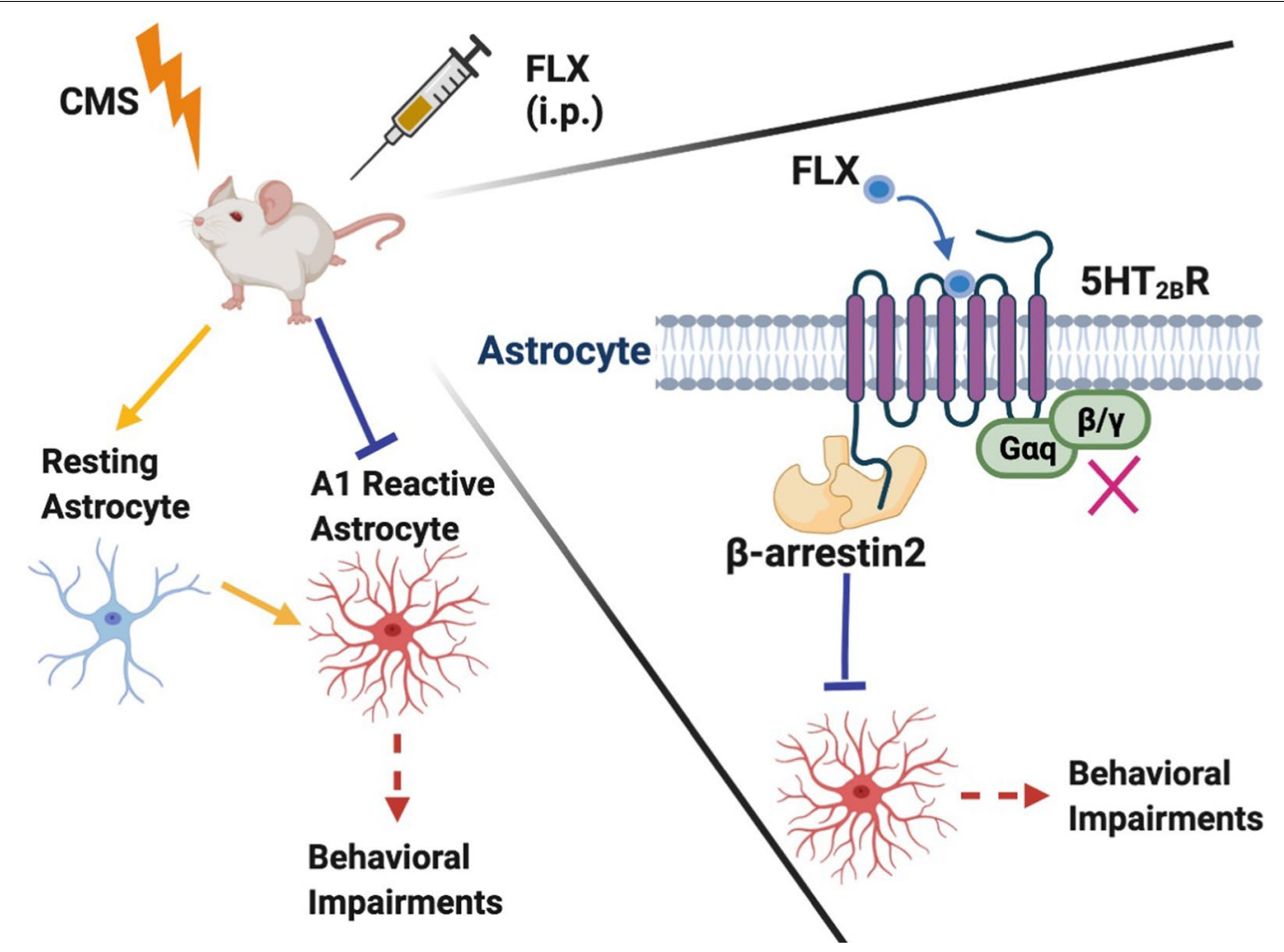

Fig.8 Schematic diagram showing inhibitory effects of fluoxetine on of A1 astrocyte reactivity in depression. Fluoxetine (FLX) administration inhibits the activation of $\mathrm{A} 1$ astrocytes in $\mathrm{CMS}$ mice and primary astrocytes via $5-\mathrm{HT}_{2 \mathrm{~B}} \mathrm{R} / \beta$-arrestin2 pathway not $\mathrm{Gq}$ protein pathway in astrocytes, which could improve behavioral impairments of CMS mice

reactivity are involved the antidepressant effects of fluoxetine in CMS mouse model and A1 phenotype regulators are likely to be therapeutic interventions of MDD.

Second, we also verified that the astrocytic $5-\mathrm{HT}_{2 \mathrm{~B}} \mathrm{R} / \beta$ arrestin2 pathway was critically involved in the effects of fluoxetine on activation of A1 astrocyte and abnormal behaviors in MDD. $5-\mathrm{HT}_{2 \mathrm{~B}} \mathrm{R}$ is one of the serotonin receptor subtypes that modulate various CNS function, such as sleep-wake cycles, emesis, appetite, mood, memory, breathing and cognition [59, 60]. In addition, the Htr $2 b$ gene, which encodes the $5-\mathrm{HT}_{2 \mathrm{~B}} \mathrm{R}$ is expressed in neonatal microglia. Ablation of this gene results in overexpression of several cytokine receptors genes under basal conditions as well as an increasing in neuroinflammatory responses upon LPS stimulation in neonatal microglia [61, 62]. Consistent with previous studies [29], we found that astrocytes expressed high levels of $5-\mathrm{HT}_{2 \mathrm{~B}} \mathrm{R}$ in the hippocampus of mice. Recent studies have highlighted that the expression of astrocytic $5-\mathrm{HT}_{2 \mathrm{~B}} \mathrm{R}$ is associated with development and treatment of MDD [63, 64]. The present data showed that both gene knockdown and pharmacological inhibitor of $5-\mathrm{HT}_{2 \mathrm{~B}} \mathrm{R}$ reversed the effects of fluoxetine on activation of $\mathrm{A} 1$ astrocyte after either A1 cocktail or IL-6 stimulation.
AAV-mediated astrocytic $5-\mathrm{HT}_{2 \mathrm{~B}} \mathrm{R}$ deficiency blocked the improved actions of fluoxetine on behavioral impairments and A1 astrocyte reactivity in hippocampus of CMS mice. The present observations together suggest that $5-\mathrm{HT}_{2 \mathrm{~B}} \mathrm{R}$ in astrocyte is involved anti-depressive roles of fluoxetine.

$5-\mathrm{HT}_{2 \mathrm{~B}} \mathrm{R}$ is a member of the GPCR family, which is the largest family of membrane protein receptors, and is the target for many drugs in treating a wide range of diseases [65]. Several studies have implied the relationship between antidepressant effects of SSRIs and $5-\mathrm{HT}_{2 \mathrm{~B}} \mathrm{R}$. For example, activation of ERK1/2 pathway induced by fluoxetine is abolished by $5-\mathrm{HT}_{2 \mathrm{~B}} \mathrm{R}$ inhibitors and siRNA-mediated $5-\mathrm{HT}_{2 \mathrm{~B}} \mathrm{R}$ deletion [66]. Another paper describes leptin enhancing the anti-depressive behaviors of fluoxetine after sleep deprivation via increasing the levels of astrocytic $5-\mathrm{HT}_{2 \mathrm{~B}} \mathrm{R}$ [64]. However, few detailed mechanisms of $5-\mathrm{HT}_{2 \mathrm{~B}} \mathrm{R}$ have been provided. The downstream signaling of GPCR activated by ligand are canonical $G$ protein pathway and non-canonical $\beta$-arrestins pathway [55]. In this study, we found that Gq protein inhibitor or knockout of $\beta$-arrestin1 failed to affect, while ablation of $\beta$-arrestin2 reversed the inhibitory functions of fluoxetine in A1 astrocyte reactivity 
in vitro. Results in vivo shown that compared with WT mice, fluoxetine administration did not affect abnormal behaviors and activation of A1 astrocyte in $\beta$-arrestin2 knockout mice after CMS stimulation. These data suggested that neither $G$ protein nor $\beta$-arrestin1 pathway participated in, whereas $\beta$-arrestin2 pathway contributed to the therapeutic actions of fluoxetine, indicating that the anti-depressive function of fluoxetine is mediated by inhibiting $\mathrm{A} 1$ astrocyte activation through astrocytic $5-\mathrm{HT}_{2 \mathrm{~B}} \mathrm{R} / \beta$-arrestin2 signaling. As $\mathrm{Gq}$ activation is involved in $5-\mathrm{HT}_{2 \mathrm{~B}} \mathrm{R}$-mediated cardiac hypertrophy that is a side-effect of $5-\mathrm{HT}_{2 \mathrm{~B}} \mathrm{R}$ agonist [53], $\beta$-arrestin2biased $5-\mathrm{HT}_{2 \mathrm{~B}} \mathrm{R}$ ligands would be a promising strategy for the development of a novel antidepressant.

\section{Conclusions}

In summary, this work indicates that fluoxetine administration improves behavioral impairments of CMS mice and inhibits the activation of A1 astrocyte in MDD in vivo and in vitro. These functions of fluoxetine are mediated by astrocytic $5-\mathrm{HT}_{2 \mathrm{~B}} \mathrm{R}$ through $\beta$-arrestin2 signaling and independent of either $\mathrm{Gq}$ protein or $\beta$-arrestin1 signaling (Fig. 8). Collectively, these results extend our understanding on $\beta$-arrestin2-biased astrocytic $5-\mathrm{HT}_{2 \mathrm{~B}} \mathrm{R}$ signaling and shed light on potential new therapeutic strategy for MDD.

\section{Abbreviations}

5- $\mathrm{HT}_{2 \mathrm{~B}} \mathrm{R}$ : 5- $\mathrm{HT}_{2 \mathrm{~B}}$ receptor; AAV: Adeno-associated virus; CMS: Chronic mild stress; CNS: Central nervous system; FBS: Fetal bovine serum; FLX: Fluoxetine; FST: Forced swimming test; GFAP: Glial fibrillary acidic protein; GPCR: G protein-coupled receptor; Iba1: Ionized calcium binding adapter molecule 1; IF: Immunofluorescence; IHC: Immunohistochemistry; IL: Interleukin; LDH: Lactate dehydrogenase; LPS: Lipopolysaccharide; MAP2: Microtubule-associated protein 2; MCM: Microglia-conditioned medium; MDD: Major depressive disorder; NC: Negative control; NDDs: Neurodegenerative diseases; NSFT: Novelty-suppressed feeding test; OFT: Open field test; PD: Parkinson's disease; PLL: Poly-L-lysine; RT: Room temperature; RT-qPCR: Quantitative real-time PCR; SERT: Serotonin transporter; siRNA: Small interfering RNA; SIT: Social interaction test; SPT: Sucrose preference test; SSRIs: Selective serotonin receptor inhibitors; TNF: Tumor necrosis factor; TST: Tail suspension test.
\end{abstract}

\section{Supplementary Information}

The online version contains supplementary material available at https://doi. org/10.1186/s12974-022-02389-y.

\footnotetext{
Additional file 1: Table S1. Primers and siRNA used in the study. Fig. S1. CMS-induced anxiety-like behaviors are reduced by fluoxetine administration. A Schematic diagram of CMS preferment and fluoxetine treatment experimental design. B-D The circuit diagram (B), bouts of mice in center (C) and duration of mice staying in center (D) in the OFT. E Latency time of mice to the first sniff in SIT. $\mathbf{F}$ Latency time of mice to the first feed $>3 \mathrm{~s}$ in NSFT. Quantitative data are mean \pm s.e. Data were analyzed using twoway ANOVA, then combined with Tukey's multiple comparison to assess the differences between groups. $\mathrm{n}=8$ per group, biologically independent animals. ${ }^{*} P<0.05,{ }^{* * P}<0.01$, and ${ }^{* *} P<0.001$. Fig. S2. A1 astrocyte reactivity in cortex of mice is protected by fluoxetine administration. $\mathbf{A}$ Heatmap of A1-special and A2-special transcripts in the cortex as analyzed by RT-qPCR. ${ }^{* * *} P<0.001$ vs control mice treated with saline; ${ }^{\# \# \# P}<0.001$
}

vs CMS mice treated with saline. B-C Expression of C3 in the cortex. D Protein levels of IL-6 in the serum, cortex and hippocampus. Quantitative data are mean \pm s.e. Data were analyzed using two-way ANOVA, then combined with Tukey's multiple comparison to assess the differences between groups. $n=4$ per group, biologically independent animals. ${ }^{*} P<0.05$, ${ }^{*} P<0.01$, and ${ }^{*}{ }^{*} P<0.001$. Fig. S3. Effects of fluoxetine on the releases of $\mathrm{LDH}$ in the supernatants of astrocyte. A Primary cultured microglia, astrocyte and neuron were sained with Iba 1, GFAP and Map2 (Scale bars, $50 \mu \mathrm{m}$ ), respectively. B-D Effects of fluoxetine on the releases of LDH in the supernatants of astrocyte after A1 (B), activated (LPS)-MCM (C) and IL-6 (D) stimulation. Quantitative data are mean \pm s.e. Data were analyzed using two-way ANOVA, then combined with Tukey's multiple comparison to assess the differences between groups. All data represent the results of three independent experiments. ${ }^{*} P<0.05,{ }^{* *} P<0.01$, and ${ }^{* * *} P<0.001$. Fig. S4 Expression of $5-\mathrm{HT}_{2 B} \mathrm{R}$ in astrocyte after transfection with siRNA for 48h. A Representative blots. B Quantitative data shown in (A). Quantitative data are mean \pm s.e. Data were analyzed using Student's $t$ test. All data represent the results of three independent experiments. ${ }^{* * *} P<0.001$. Fig. S5 AAV-mediated depletion of $5-\mathrm{HT}_{2 \mathrm{~B}} \mathrm{R}$ in astrocyte. A Schematic representation of the AAV virus construct used to express $5-\mathrm{HT}_{2 \mathrm{~B}} \mathrm{R}$ or control siRNA in astrocyte under the gfaABC1D promoter. B Protein levels of $5-\mathrm{HT}_{2 B} \mathrm{R}$ in the hippocampus of mice after $\mathrm{AAV}$ injection for 4 weeks. Quantitative data are mean \pm s.e. Data were analyzed using Student's $t$ test. All data represent the results of three independent experiments. ${ }^{* *} P<0.001$. C Expression of $5-\mathrm{HT}_{2 B} \mathrm{R}$ on astrocyte in the hippocampus DG of mice. Scale bars, $20 \mu \mathrm{m}$. Similar results were obtained in three separate experiments. D Schematic diagram of AAV injection experimental design. Fig. S6. Astrocytic $5-\mathrm{HT}_{2 \mathrm{~B}} \mathrm{R}$ knockdown reverses the functions of fluoxetine in anxiety-like behaviors and the expression of A1-special markers in cortex of mice. A-C The circuit diagram (A), bouts of mice in center (B) and duration of mice with or without fluoxetine treatment after AAV injection staying in center (C) in the OFT. D Latency time of mice to the first sniff in SIT. $\mathbf{E}$ Latency time of mice to the first feed $>3 \mathrm{~s}$ in NSFT. $\mathbf{F}$ Levels of A1-special genes in the cortex of CON and CMS mice after $A A \bigvee$ injection. Quantitative data are mean \pm s.e. Data were analyzed using two-way ANOVA, then combined with Tukey's multiple comparison to assess the differences between groups. B-E: $n=8(\mathbf{C}, \mathbf{E}), n$ $=9$ (B, D) CON with Control AAV and saline; $n=8(\mathbf{C}, \mathbf{E}), n=9(\mathbf{B}, \mathbf{D})$ CON with Control AAV and FLX; $n=8$ (D, E), $n=9$ (B, C) CMS with Control AAV and saline; $n=8$ (B, E), $n=9$ (C, D) CMS with Control AAV and FLX; $n=$ $8 \mathrm{CON}$ with $\mathrm{mHT}_{2 \mathrm{~B}} \mathrm{R}$ AAV and saline; $n=8(\mathbf{D}, \mathbf{E}), n=9$ (B, C) CON with $\mathrm{mHT}_{2 \mathrm{~B}} \mathrm{R} A \mathrm{AAV}$ and $\mathrm{FLX} ; \mathrm{n}=8(\mathbf{E}), n=9$ (B-D) CMS with $\mathrm{mHT}_{2 \mathrm{~B}} \mathrm{R} A \mathrm{~A}$. $\mathrm{C}$ and saline; $n=8(\mathbf{B}, \mathbf{D}, \mathbf{E}), n=9$ (C) CMS with $\mathrm{mHT}_{2 \mathrm{~B}} \mathrm{R} \mathrm{AAV}$ and FLX; $\mathbf{F}: n=4$ per group; biologically independent animals. ${ }^{*} P<0.05$, and ${ }^{* *} P<0.001$ vs respective control mice treated with saline; ${ }^{\#} P<0.05$, and ${ }^{\# \# \#} P<0.001$ vs CMS mice injected with control AAV and treated with saline; ${ }^{\$} P<0.05$, $\$ \$ p<0.01$, and ${ }^{\$ \$} \$ p<0.001$. Fig. $\mathbf{S 7}$. $\beta$-arrestin 2 is contribute to the effects of fluoxetine on $\mathbf{A} 1$ astrocyte reactivity in vitro. $\mathbf{A}$ Expression of $\beta$-arrestin 1 in primary astrocyte isolated from WT and $\beta$-arrestin 1 knockout mice. B Expression of $\beta$-arrestin 2 in primary astrocyte of isolated from WT and $\beta$-arrestin 2 knockout mice. C Effects of $\beta$-arrestin 2 knockout on the levels of A1-special genes in astrocyte with or without fluoxetine treatment after activated (LPS)-MCM stimulation. Quantitative data are mean \pm s.e. Data were analyzed using two-way ANOVA, then combined with Tukey's multiple comparison to assess the differences between groups. All data represent the results of three independent experiments. ${ }^{* * *} P<0.001$ vs respective control cells treated with non-activated $\mathrm{MCM}^{*}{ }^{\# \#} P<0.01$, and ${ }^{\# \# \# P<0.001 \text { vs WT control cells treated with LPS-MCM stimulation; } \$ \$ p<}$ 0.01 , and ${ }^{\$ \$} P<0.001$. Fig. S8. $\beta$-arrestin 2 knockout reduces the effects of fluoxetine on the expression of A1-special markers in cortex of CMS mice. A-C The circuit diagram (A), bouts of WT and $\beta$-arrestin 2 knockout mice in center (B) and durationof WT and $\beta$-arrestin 2 knockout mice staying in center $(\mathbf{C})$ in the OFT. D Latency time of mice to the first sniff in SIT. $\mathbf{E}$ Latency time of mice to the first feed $>3 \mathrm{~s}$ in NSFT. $\mathbf{F}$ Levels of A1-special genes in the cortex of WT and $\beta$-arrestin $2^{-/-}$mice. Data were analyzed using two-way ANOVA, then combined with Tukey's multiple comparison to assess the differences between groups. Quantitative data are mean \pm s.e. B-E: $n=8$ (D, E), $n=9$ (B, C) WT CON with saline; $n=8$ (C-E), $n=$ 9 (B) WT CON with FLX; $n=8$ (D, E), $n=10$ (B, C) WT CMS with saline; $n$ 
$=8(\mathbf{D}, \mathbf{E}), n=9$ (B, C) WT CMS with FLX; $\mathrm{n}=8(\mathbf{E}), \mathrm{n}=9(\mathbf{B}, \mathbf{C}), \mathrm{n}=10$ (D) $\beta$-arrestin $2^{-1-}$ CON with saline; $n=8$ (B, D, E), $n=9$ (C) $\beta$-arrestin $2^{-1-}$ CON with $\mathrm{FLX} ; \mathrm{n}=8 \beta$-arrestin $2^{-/-}$CMS with saline; $n=8(\mathbf{D}, \mathbf{E}), n$ $=9(\mathbf{B}, \mathbf{C}) \beta$-arrestin $2^{-/-}$CMS with FLX; F: $n=4$ per group; biologically independent animals. ${ }^{* *} P<0.001$ vs respective control mice treated with saline; ${ }^{\#} P<0.05$, and ${ }^{\# \# \#} P<0.001$ vs WT CMS mice treated with saline; ${ }^{\$} P<$ 0.05 , ${ }^{\$ \$} P<0.01$, and ${ }^{\$ \$} P<0.001$. Fig. $\mathbf{S 9}$. The overall experimental design of this study.

Additional file 2. ANOVA results.

\section{Acknowledgements}

Not applicable.

\section{Authors' contributions}

In this study, YF, GH, XD, ML, and JD conceived and designed the experiments. $Y F, X D, Y Z, L C, K M, R X, S L, M S, H Z$ and $J L$ carried out experiments. YF, XD, YG, $\mathrm{GH}$, and $\mathrm{ML}$ analyzed and interpreted the data. YF and XD wrote the paper. $\mathrm{GH}$ critically reviewed and edited the work. YF and XD contributed equally to this work. All authors read and approved the final manuscript.

\section{Funding}

The work reported herein was supported by the grants from the National Natural Science Foundation of China (No.81630099 and No.81991523 to GH, and 81703488 to YF), the Drug Innovation Major Project (No. 2018ZX0971 1001003-007 to GH), the and Natural Science Foundation of the Basic Research Program of Jiangsu Province (No. BK20171061 to YF).

\section{Availability of data and materials}

Supporting data and information about used material are available from the corresponding author on reasonable request.

\section{Declarations}

\section{Ethics approval and consent to participate}

All animal experiments were carried out in compliance with the ethical regulations and approved by Institutional Animal Care and Use Committee (IACUC) of the Nanjing Medical University Experimental Animal Department (IACUC1903038).

\section{Consent for publication}

Not applicable.

\section{Competing interests}

The authors declare that they have no conflict of interest.

\section{Author details}

'Jiangsu Key Laboratory of Neurodegeneration, Department of Pharmacology, Nanjing Medical University, 101 Longmian Avenue, Nanjing 211166, Jiangsu, China. ${ }^{2}$ Department of Pharmacology, Nanjing University of Chinese Medicine, 138 Xianlin Avenue, Nanjing 210023, Jiangsu, China.

\section{Received: 29 August 2021 Accepted: 17 January 2022}

Published online: 29 January 2022

\section{References}

1. Global, regional, and national incidence, prevalence, and years lived with disability for 354 diseases and injuries for 195 countries and territories, 1990-2017: a systematic analysis for the Global Burden of Disease Study 2017. Lancet 2018, 392:1789-1858.

2. Ménard C, Hodes GE, Russo SJ. Pathogenesis of depression: Insights from human and rodent studies. Neuroscience. 2016;321:138-62.

3. Krishnan V, Nestler EJ. The molecular neurobiology of depression. Nature. 2008:455:894-902.

4. Schmidt HD, Shelton RC, Duman RS. Functional biomarkers of depression: diagnosis, treatment, and pathophysiology. Neuropsychopharmacology. 2011;36:2375-94.
5. Battle DE. Diagnostic and statistical manual of mental disorders (DSM). Codas. 2013;25:191-2.

6. Shadrina M, Bondarenko EA, Slominsky PA. Genetics factors in major depression disease. Front Psychiatry. 2018;9:334.

7. Köhler CA, Evangelou E, Stubbs B, Solmi M, Veronese N, Belbasis L, Bortolato B, Melo MCA, Coelho CA, Fernandes BS, et al. Mapping risk factors for depression across the lifespan: an umbrella review of evidence from meta-analyses and Mendelian randomization studies. J Psychiatr Res. 2018:103:189-207.

8. Postal M, Appenzeller S. The importance of cytokines and autoantibodies in depression. Autoimmun Rev. 2015;14:30-5.

9. Frizzo ME, Ohno Y. Perisynaptic astrocytes as a potential target for novel antidepressant drugs. J Pharmacol Sci. 2021;145:60-8.

10. Verkhratsky A, Nedergaard M. Physiology of astroglia. Physiol Rev. 2018;98:239-389.

11. Khakh BS. Astrocyte-neuron interactions in the striatum: insights on identity, form, and function. Trends Neurosci. 2019;42:617-30.

12. Pekny M, Pekna M. Astrocyte reactivity and reactive astrogliosis: costs and benefits. Physiol Rev. 2014;94:1077-98.

13. Sofroniew MV. Astrocyte reactivity: subtypes, states, and functions in CNS innate immunity. Trends Immunol. 2020;41:758-70.

14. Liddelow SA, Guttenplan KA, Clarke LE, Bennett FC, Bohlen CJ, Schirmer L, Bennett ML, Münch AE, Chung W-S, Peterson TC, et al. Neurotoxic reactive astrocytes are induced by activated microglia. Nature. 2017;541:481-7.

15. Diaz-Castro B, Gangwani MR, Yu X, Coppola G, Khakh BS. Astrocyte molecular signatures in Huntington's disease. Science Transl Med. 2019. https://doi.org/10.1126/scitransImed.aaw8546.

16. Sun S, Sun Y, Ling S-C, Ferraiuolo L, MCAlonis-Downes M, Zou Y, Drenner K, Wang Y, Ditsworth D, Tokunaga S, et al. Translational profiling identifies a cascade of damage initiated in motor neurons and spreading to glia in mutant SOD1-mediated ALS. Proc Natl Acad Sci USA. 2015;112:E6993-7002.

17. Yun SP, Kam T-I, Panicker N, Kim S, Oh Y, Park J-S, Kwon S-H, Park YJ, Karuppagounder SS, Park H, et al. Block of A1 astrocyte conversion by microglia is neuroprotective in models of Parkinson's disease. Nat Med. 2018;24:931-8.

18. Gritti D, Delvecchio G, Ferro A, Bressi C, Brambilla P. Neuroinflammation in major depressive disorder: a review of PET imaging studies examining the 18-kDa translocator protein. J Affect Disord. 2021;292:642-51.

19. Nettis MA, Pariante CM. Is there neuroinflammation in depression? Understanding the link between the brain and the peripheral immune system in depression. Int Rev Neurobiol. 2020;152:23-40.

20. Zhang H-Y, Wang Y, He Y, Wang T, Huang X-H, Zhao C-M, Zhang L, Li S-W, Wang C, Qu Y-N, Jiang X-X. A1 astrocytes contribute to murine depression-like behavior and cognitive dysfunction, which can be alleviated by IL-10 or fluorocitrate treatment. J Neuroinflammation. 2020;17:200.

21. Hao T, Du X, Yang S, Zhang Y, Liang F. Astrocytes-induced neuronal inhibition contributes to depressive-like behaviors during chronic stress. Life Sci. 2020;258:118099.

22. Almeida IB, Gomes IA, Shanmugam S, de Moura TR, Magalhães LS, de Aquino LAG, de Souza Araújo AA, Oliveira PD, Santos MRV. Inflammatory modulation of fluoxetine use in patients with depression: a systematic review and meta-analysis. Cytokine. 2020;131:155100.

23. Perez-Caballero L, Torres-Sanchez S, Bravo L, Mico JA, Berrocoso E. Fluoxetine: a case history of its discovery and preclinical development. Expert Opin Drug Discov. 2014;9:567-78.

24. Roumestan C, Michel A, Bichon F, Portet K, Detoc M, Henriquet C, Jaffuel D, Mathieu M. Anti-inflammatory properties of desipramine and fluoxetine. Respir Res. 2007;8:35.

25. Levy MJF, Boulle F, Emerit MB, Poilbout C, Steinbusch HWM, Van den Hove DLA, Kenis G, Lanfumey L. 5-HTT independent effects of fluoxetine on neuroplasticity. Sci Rep. 2019;9:6311.

26. Shu X, Sun Y, Sun X, Zhou Y, Bian Y, Shu Z, Ding J, Lu M, Hu G. The effect of fluoxetine on astrocyte autophagy flux and injured mitochondria clearance in a mouse model of depression. Cell Death Dis. 2019;10:577.

27. Kinoshita M, Hirayama Y, Fujishita K, Shibata K, Shinozaki Y, Shigetomi E, Takeda A, Le HPN, Hayashi H, Hiasa M, et al. Anti-depressant fluoxetine reveals its therapeutic effect via astrocytes. EBioMedicine. 2018;32:72-83.

28. Peng L, Gu L, Li B, Hertz L. Fluoxetine and all other SSRIs are 5-HT2B agonists-importance for their therapeutic effects. Curr Neuropharmacol. 2014:12:365-79. 
29. Yue T, Li B, Gu L, Huang J, Verkhratsky A, Peng L. Ammonium induced dysfunction of 5-HT receptor in astrocytes. Neurochem Int. 2019;129:104479.

30. Li C-X, Zheng Y, Zhu H, Li C-W, He Z, Wang C, Ding J-H, Hu G, Lu M. $\beta$-arrestin 2 is essential for fluoxetine-mediated promotion of hippocampal neurogenesis in a mouse model of depression. Acta Pharmacol Sin. 2021;42:679-90

31. Diaz S, Doly S, Narboux-Nême N, Fernández S, Mazot P, Banas S, Boutourlinsky K, Moutkine I, Belmer A, Roumier A. Maroteaux LJMp: 5-HT(2B) receptors are required for serotonin-selective antidepressant actions. Mol Psychiatry. 2012;17:154-63.

32. Willner P, Muscat R, Papp M. Chronic mild stress-induced anhedonia: a realistic animal model of depression. Neurosci Biobehav Rev. 1992;16:525-34.

33. Zhang Y, Du L, Bai Y, Han B, He C, Gong L, Huang R, Shen L, Chao J, Liu P, et al. CircDYM ameliorates depressive-like behavior by targeting miR-9 to regulate microglial activation via HSP90 ubiquitination. Mol Psychiatry. 2020;25:1175-90.

34. Can A, Dao DT, Arad M, Terrillion CE, Piantadosi SC, Gould TD. The mouse forced swim test. JoVE. 2012. https://doi.org/10.3791/3638.

35. Ostadhadi S, Norouzi-Javidan A, Chamanara M, Akbarian R, Imran-Khan M, Ghasemi M, Dehpour A-R. Involvement of NMDA receptors in the antidepressant-like effect of tramadol in the mouse forced swimming test. Brain Res Bull. 2017;134:136-41.

36. Zhang Q, Sun Y, He Z, Xu Y, Li X, Ding J, Lu M, Hu G. Kynurenine regulates NLRP2 inflammasome in astrocytes and its implications in depression. Brain Behav Immun. 2020;88:471-81.

37. Stukalin Y, Lan A, Einat H. Revisiting the validity of the mouse tail suspension test: systematic review and meta-analysis of the effects of prototypic antidepressants. Neurosci Biobehav Rev. 2020;112:39-47.

38. Cryan JF, Mombereau C, Vassout A. The tail suspension test as a model for assessing antidepressant activity: review of pharmacological and genetic studies in mice. Neurosci Biobehav Rev. 2005;29:571-625.

39. Kraeuter A-K, Guest PC, Sarnyai Z: The Open Field Test for Measuring Locomotor Activity and Anxiety-Like Behavior. Methods in molecular biology (Clifton, NJ) 2019, 1916. https://doi.org/10.1007/ 978-1-4939-8994-2_9

40. Iwata M, Ota KT, Li X-Y, Sakaue F, Li N, Dutheil S, Banasr M, Duric V, Yamanashi T, Kaneko K, et al. Psychological stress activates the inflammasome via release of adenosine triphosphate and stimulation of the purinergic type 2X7 receptor. Biol Psychiat. 2016;80:12-22

41. Li MX, Zheng HL, Luo Y, He JG, Wang W, Han J, Zhang L, Wang X, Ni L, Zhou HY, et al. Gene deficiency and pharmacological inhibition of caspase- 1 confers resilience to chronic social defeat stress via regulating the stability of surface AMPARs. Mol Psychiatry. 2018;23:556-68.

42. Fang $Y$, Jiang $Q$, Li S, Zhu H, Xu R, Song N, Ding X, Liu J, Chen M, Song M, et al. Opposing functions of $\beta$-arrestin 1 and 2 in Parkinson's disease via microglia inflammation and Nprl3. Cell Death Differ. 2021;28:1822-36.

43. Zhu J, Hu Z, Han X, Wang D, Jiang Q, Ding J, Xiao M, Wang C, Lu M, Hu G. Dopamine D2 receptor restricts astrocytic NLRP3 inflammasome activation via enhancing the interaction of $\beta$-arrestin2 and NLRP3. Cell Death Differ. 2018;25:2037-49.

44. Hisaoka-Nakashima K, Miyano K, Matsumoto C, Kajitani N, Abe H, OkadaTsuchioka M, Yokoyama A, Uezono Y, Morioka N, Nakata Y, Takebayashi M. Tricyclic antidepressant amitriptyline-induced glial cell line-derived neurotrophic factor production involves pertussis toxin-sensitive gai/o activation in astroglial cells. J Biol Chem. 2015;290:13678-91.

45. Fang Y, Yao L, Li C, Wang J, Wang J, Chen S, Zhou X-F, Liao H. The blockage of the Nogo/NgR signal pathway in microglia alleviates the formation of A $\beta$ plaques and tau phosphorylation in APP/PS1 transgenic mice. J Neuroinflammation. 2016:13:56.

46. Han X, Sun S, Sun Y, Song Q, Zhu J, Song N, Chen M, Sun T, Xia M, Ding J, et al. Small molecule-driven NLRP3 inflammation inhibition via interplay between ubiquitination and autophagy: implications for Parkinson disease. Autophagy. 2019;15:1860-81.

47. Kim J, Castellano JM, Jiang H, Basak JM, Parsadanian M, Pham V, Mason SM, Paul SM, Holtzman DM. Overexpression of low-density lipoprotein receptor in the brain markedly inhibits amyloid deposition and increases extracellular A beta clearance. Neuron. 2009;64:632-44.

48. Feng W, Zhang Y, Wang Z, Xu H, Wu T, Marshall C, Gao J, Xiao M. Microglia prevent beta-amyloid plaque formation in the early stage of an
Alzheimer's disease mouse model with suppression of glymphatic clearance. Alzheimer's Res Ther. 2020;12:125.

49. Xu Z, Xiao N, Chen Y, Huang H, Marshall C, Gao J, Cai Z, Wu T, Hu G, Xiao M. Deletion of aquaporin-4 in APP/PS1 mice exacerbates brain A $\beta$ accumulation and memory deficits. Mol Neurodegener. 2015;10:58.

50. Livak KJ, Schmittgen TD. Analysis of relative gene expression data using real-time quantitative PCR and the 2(-Delta Delta C(T)) Method. Methods (San Diego, Calif). 2001;25:402-8.

51. Colasanto M, Madigan S, Korczak DJ. Depression and inflammation among children and adolescents: a meta-analysis. J Affect Disord. 2020;277:940-8.

52. Köhler CA, Freitas TH, Maes M, de Andrade NQ, Liu CS, Fernandes BS, Stubbs B, Solmi M, Veronese N, Herrmann N, et al. Peripheral cytokine and chemokine alterations in depression: a meta-analysis of 82 studies. Acta Psychiatr Scand. 2017;135:373-87.

53. McCorvy JD, Roth BL. Structure and function of serotonin G proteincoupled receptors. Pharmacol Ther. 2015;150:129-42.

54. Liu Y, Wang Z, Li J, Ban Y, Mao G, Zhang M, Wang M, Liu Y, Zhao B, Shen $Q$, et al. Inhibition of 5-hydroxytryptamine receptor $2 B$ reduced vascular restenosis and mitigated the $\beta$-arrestin2-mammalian target of rapamycin/p70S6K pathway. J Am Heart Assoc. 2018. https://doi.org/10.1161/ JAHA.117.006810.

55. Bond RA, Lucero Garcia-Rojas EY, Hegde A, Walker JKL. Therapeutic potential of targeting ß-arrestin. Front Pharmacol. 2019;10:124.

56. Hinkle JT, Dawson VL, Dawson TM. The A1 astrocyte paradigm: New avenues for pharmacological intervention in neurodegeneration. Move Disord. 2019;34:959-69.

57. O'Leary LA, Mechawar N. Implication of cerebral astrocytes in major depression: a review of fine neuroanatomical evidence in humans. Glia. 2021. https://doi.org/10.1002/glia.23994.

58. Zhang J, Ning L, Wang J. Dietary quercetin attenuates depressive-like behaviors by inhibiting astrocyte reactivation in response to stress. Biochem Biophys Res Commun. 2020;533:1338-46.

59. Ray RS, Corcoran AE, Brust RD, Kim JC, Richerson GB, Nattie E, Dymecki SM. Impaired respiratory and body temperature control upon acute serotonergic neuron inhibition. Science (New York, NY). 2011;333:637-42.

60. Berger M, Gray JA, Roth BL. The expanded biology of serotonin. Annu Rev Med. 2009:60:355-66.

61. Kolodziejczak M, Béchade C, Gervasi N, Irinopoulou T, Banas SM, Cordier C, Rebsam A, Roumier A, Maroteaux L. Serotonin modulates developmental microglia via 5-HT2B receptors: potential implication during synaptic refinement of retinogeniculate projections. ACS Chem Neurosci. 2015;6:1219-30.

62. Béchade C, D'Andrea I, Etienne F, Verdonk F, Moutkine I, Banas SM, Kolodziejczak M, Diaz SL, Parkhurst CN, Gan WB, et al. The serotonin 2B receptor is required in neonatal microglia to limit neuroinflammation and sickness behavior in adulthood. Glia. 2021;69:638-54.

63. Peng L, Song D, Li B, Verkhratsky A. Astroglial 5-HT receptor in mood disorders. Expert Rev Neurother. 2018;18:435-42.

64. Li X, Liang S, Li Z, Li S, Xia M, Verkhratsky A, Li B. Leptin increases expression of 5-HT receptors in astrocytes thus enhancing action of fluoxetine on the depressive behavior induced by sleep deprivation. Front Psych. 2018;9:734.

65. Campbell AP, Smrcka AV. Targeting G protein-coupled receptor signalling by blocking G proteins. Nat Rev Drug Discovery. 2018;17:789-803.

66. Li B, Zhang S, Zhang H, Nu W, Cai L, Hertz L, Peng L. Fluoxetine-mediated 5 -HT2B receptor stimulation in astrocytes causes EGF receptor transactivation and ERK phosphorylation. Psychopharmacology. 2008;201:443-58.

\section{Publisher's Note}

Springer Nature remains neutral with regard to jurisdictional claims in published maps and institutional affiliations. 